\title{
Palinotaxonomia de espécies de Lepidaploa (Cass.) Cass. (Vernoniinae - Compositae) ocorrentes no Sudeste do Brasil ${ }^{1}$
}

\author{
CLÁUDIA BARBIERI FERREIRA MENDONÇA ${ }^{2,4}$, ROBERTO LOURENÇO ESTEVES ${ }^{3} \mathrm{e}$ \\ VANIA GONÇALVES-ESTEVES ${ }^{2}$
}

(recebido: 19 de janeiro de 2006; aceito: 7 de dezembro de 2006)

\begin{abstract}
Palynotaxonomy of species of Lepidaploa (Cass.) Cass. (Vernoniinae - Compositae) from southeastern Brazil). The pollinic study of 23 species of Lepidaploa that occur in southeastern Brazil was done with the objetive of contributing to the pollinic characterization of these species and also evaluating its taxonomic position. The pollen grains were acetolysed, measured, described and ilustrated under light microscopy. For further details of pollen surface and aperture, non acetolysed pollen grains were analysed by scanning electron microscopy (SEM) and, subsequently, electron-micrographed. Characteristics of pollen grains like shape, size and constitution of exine and aperture were studied. The pollen of the species analysed in this study varies from medium or large in size, isopolar, suboblate, oblate spheroidal or prolate spheroidal, subtriangular ambit, small or large polar area, 3-colporate with echinolophate surface. A key to identify the studied species was made based on pollinic data. Pollen grains from Lepidaploa have four main brochus organization pattern of the echinolophate exine. Three of these patterns can be divided into subtypes according to the apertural lacune shape.
\end{abstract}

Key words - Compositae, Lepidaploa, palynology, southeast Brazil, Vernoniinae

RESUMO - (Palinotaxonomia de espécies de Lepidaploa (Cass.) Cass. (Vernoniinae - Compositae) ocorrentes no Sudeste do Brasil). Foi realizado o estudo polínico de 23 espécies de Lepidaploa (Cass.) Cass. (Vernoniinae-Compositae) ocorrentes no Sudeste do Brasil, com o objetivo de contribuir para a caracterização polínica dessas espécies, bem como avaliar sua posição taxonômica. Os grãos de pólen foram acetolisados, medidos, descritos e ilustrados sob microscópia de luz. Para observar detalhes da superfície e da abertura, grãos de pólen não acetolizados foram analisados em microscópio eletrônico de varredura (MEV) e, em seguida, eletromicrografados. Foram estudadas as características dos grãos de pólen como forma, tamanho, constituição da exina e abertura. As espécies analisadas nesse estudo possuem grãos de pólen de tamanho médios ou grandes, isopolares, suboblatos, oblato-esferoidais ou prolato-esferoidais, âmbito subtriangular, área polar pequena ou grande, 3-colporados de superfície equinolofada. Foi confeccionada uma chave para identificação das espécies estudadas com base em dados polínicos. Pôde-se concluir que os grãos de pólen do gênero Lepidaploa apresentam quatro padrões principais de organização das malhas da exina equinolofada e três desses padrões podem ser divididos em subtipos de acordo com a forma da lacuna apertural.

Palavras-chave - Compositae, Lepidaploa, palinologia, Sudeste brasileiro, Vernoniinae

\section{Introdução}

A família Asteraceae compreende 1.535 gêneros, com cerca de 23.000 espécies (Bremer 1994). Segundo Hind (1993), cerca de metade das espécies de Asteraceae ocorre no Novo Mundo, com predomínio na América Latina, sendo estimadas, para a flora

\footnotetext{
1. Parte da tese do primeiro autor, Programa de Pós-graduação em Ciências Biológicas (Botânica), Museu Nacional/ Universidade Federal do Rio de Janeiro.

2. Universidade Federal do Rio de Janeiro, Museu Nacional, Departamento de Botânica, Laboratório de Palinologia, Quinta da Boa Vista, São Cristóvão, 20940-040 Rio de Janeiro, RJ, Brasil.

3. Universidade do Estado do Rio de Janeiro, Instituto de Biologia, IBRAG/DBV, Rua São Francisco Xavier, 524, Maracanã, 2550-013 Rio de Janeiro, RJ, Brasil.

4. Autor para correspondência: mendonca@mn.ufrj.br
}

brasileira, cerca de 3.000 espécies que são, particularmente, abundantes nos ecossistemas de cerrado, campo rupestre, campo de altitude e restinga, estando ausente ou muito pobremente representada, na floresta tropical úmida.

A tribo Vernonieae Cass., com 98 gêneros e cerca de 1.400 espécies, possui uma distribuição principalmente tropical com dois principais centros de distribuição: Brasil e África tropical (Hind 1993). A tribo compreende ervas anuais ou perenes, arbustos, lianas e, raramente, árvores de grande porte. As folhas são em geral alternas, com venação pinada, capítulos discóides, homógamos e ramos do estilete longos, subulados, com pilosidade se estendendo abaixo do ponto de bifurcação (Bremer 1994). Os grãos de pólen possuem, geralmente, espinhos dispostos em padrões regulares do tipo equinolofados (Jones 1979). 
A tribo Vernonieae, sob o ponto de vista taxonômico, tem sido considerada um dos grupos mais complexos de Asteraceae. Numa série de estudos sobre Vernonieae, Robinson (1987a, 1988a, b, 1990, 1996, 1999) alterou, substancialmente, a circunscrição tradicional de Vernonia, fragmentando-o em diversos novos gêneros, ficando o gênero Vernonia s.str. restrito quase que exclusivamente à América do Norte. Entretanto, esta nova classificação não tem sido adotada por alguns autores (Keeley \& Turner 1990, Hind 1993, 1999, Keeley \& Jansen 1994, Mendonça \& GonçalvesEsteves 2000), que têm considerado prematura a elevação de seções e subseções de Vernonia Schreb. para o nível genérico o que não resolve o problema taxonômico. Certamente a posição de algumas espécies de Vernonia são ainda questionáveis uma vez que faltam informações importantes em várias áreas como citologia, biologia molecular, química, genética e palinologia.

Lepidaploa foi nomeado originalmente por Cassini (1817 apud King \& Dawson 1975) como um subgênero de Vernonia. De Candole (1836), não reconheceu Lepidaploa como gênero e o colocou como uma seção de Vernonia, contendo 195 espécies incluindo algumas da Ásia e África (Bremer 1994). Baker (1873), na "Flora Brasiliensis...." manteve Lepidaploa como uma seção de Vernonia, enquadrando nessa seção a maioria das espécies brasileiras. A relação filogenética em Vernonia continuou pobremente compreendida e a divisão infragenérica aceita por Baker (1873) sofreu algumas alternativas de classificação que foram sugeridas por Cabrera (1944), Keeley (1978), Jones $(1979,1981)$.

Robinson (1990) elevou novamente Lepidaploa ao status genérico com base numa série de características de hábito, indumento, inflorescência, da relação entre brácteas involucrais/flores e grãos de pólen lofados com columela "rizomatosa" ou "rizomatomiforme", classificados como tipo $\mathrm{C}$, tipo $\mathrm{D}$, tipo $\mathrm{G}$ e raramente o tipo A.

O levantamento palinológico mostrou que vários autores analisaram os grãos de pólen de espécies de Asteraceae, principalmente, de Vernonia s.l. Wodehouse (1935) foi o primeiro a reconhecer três padrões de ornamentação: psilado, equinado e lofado; Erdtman (1952) destacou a variabilidade na abertura, no tamanho, na forma e na ornamentação da exina; Stix (1960) criou 42 tipos polínicos para a família com base na estrutura da exina quando observada em microscopia de luz e eletrônica de transmissão. Outros autores como Skvarla \& Turner (1966), Smith (1969), Moreira (1969), Salgado-Labouriau (1973), Nair \& Lawrence (1985),
Roubik \& Moreno (1991), Skvarla et al. (1977), Bolick \& Keeley (1994), Mendonça \& Gonçalves-Esteves (2000), Skvarla et al. (2005) estudaram, palinologicamente, espécies de Asteraceae e, particularmente, de Vernonia, utilizando, ou não os tipos criados por Stix (1960). É importante frizar que a partir de 1966, surgiram publicações sobre os grãos de pólen de Vernonia onde os autores criaram diversos tipos polínicos com base naqueles de Stix (1960). Os principais foram: Jones (1970, 1973, 1981, 1982), Kingham (1976), Kelley \& Jones (1977, 1979), Vasanthy et al. (1993) e Robinson (1990, 1994, 1999). Este último, reforçando a fragmentação de Vernonia s.l. em diferentes gêneros com base, principalmente, nas características palinológicas.

O presente trabalho objetiva a caracterização morfopalinológica e a identificação de caracteres de valor diagnóstico, de espécies de Lepidaploa, ocorrentes na região Sudeste do Brasil, com a finalidade de oferecer aos taxonomistas subsídios para avaliar a nova organização feita por Robinson (1999).

\section{Material e métodos}

Estudou-se a morfologia polínica de 23 espécies de Lepidaploa, a saber: L. argyrotricha (Sch. Bip. ex Baker) H. Rob., L. aurea (Mart. ex DC.) H. Rob., L. barbata (Less.) H. Rob., L. chamissonis (Less.) H. Rob., L. cotoneaster (Willd. ex Spreng.) H. Rob., L. coulonioides (H. Rob.) H. Rob., L. decumbens (Gardner) H. Rob., L. eriolepis (Gardner) H. Rob., L. gnaphalioides (Sch. Bip. ex Baker) H. Rob., L. gracilis (H.B.K.) H. Rob., L. helophila (Mart. ex DC.) H. Rob., L. lilacina (Mart. ex DC.) H. Rob., L. macahensis (Glaz. ex G.M. Barroso) H. Rob., L. muricata (DC.) H. Rob., L. obtusifolia (Less.) H. Rob., L. psilostachya (DC.) H. Rob., L. remotiflora (L.C. Rich.) H. Rob., L. salzmannii (DC.) H. Rob., L. sericea (L.C. Rich.) H. Rob., L. sororia (DC.) H. Rob., L. spixiana (Mart. ex DC.) H. Rob., L. subsquarrosa (DC.) H. Rob. e L. vauthieriana (DC.) H. Rob.

O material polínico utilizado foi obtido a partir de anteras férteis de flores em antese e/ou botões bem desenvolvidos, de exsicatas pertencentes aos herbários nacionais, abaixo relacionados, de acordo com o Index Herbariorum (Holmgren et al. 1990): CESJ, GUA, MBM, R, RB, SPF, HUFU, VIC.

Para cada espécie estudada foi escolhido um espécime considerado "padrão", o qual foi utilizado para a realização das descrições e ilustrações apresentando-se na relação a seguir, indicado por um asterisco (*) anteposto ao nome do coletor. Sempre que possível, foram analisados até quatro espécimes de comparação, para confirmação dos resultados obtidos. As lâminas utilizadas no estudo encontram-se depositadas na Palinoteca do Laboratório de Palinologia Álvaro Xavier Moreira, do Departamento de Botânica do 
Museu Nacional/Universidade Federal do Rio de Janeiro.

Material examinado: Lepidaploa argyrotricha - BRASIL. Minas Gerais: Belo Horizonte, Mazarapão, 13-VII-1956, * L. Roth s.n. (MBM256589); Francisco Dumont, Serra do Cabral, 16-V-2001, G. Hatschbach et al. 72105 (MBM); RIO DE JANEIRO: Cabo Frio, 20-21-III-1943, José Vidal s.n. (R39505); SÃo PaUlo: Estação Experimental de Itirapina, 29-IV-1977, E. Giannotti et al. 5500 (MBM). L. aurea - BRASIL. MinAs GERAIS: Buritizeiro, 13-V-2001, G. Hatschbach et al. 71936 (MBM); Chapada de Contagem, 22-VI-1982, *T.B. Croat 53662 (GUA); Pirapora, 13-IV-1996, G. Hatschbach 64610 et al. (MBM). L. barbata - BRASIL. MINAS GERAIS: Belo Horizonte, Serra do Taquaril, 10-VIII-1932, *Melo Barreto 8431 (R); Diamantina, Bocaiúva, 23-VII-1998, G. Hatschbach et al. 68114 (MBM); Elorada Nova, V-1962, L. Netto s.n. (R15237); Itabuirto, Serra da Moeda, 18-IX-1985, G. Hatschbach 49827 \& F.J. Zelma (MBM); Rio Claro, VII-1946, Gardner 4799 (R). L. chamissonis - BRASIL. SÃo PAulo: Agudos, Fazenda Monte Alegre, 31-V-2000, *M.E.S. Paschoal \& A.C. Desteffani 2237 (HUFU); Agudos, 17-V-2000, M.E.S. Paschoal \& J.R. Fabricante s.n. (HUFU 27746). L. cotoneaster - BRASIL. Minas Gerais: Manhuaçu, 21-VII-1982, G. Hatschbach 45153 \& O. Guimarães s.n. (MBM); Marliéria, Estrada do Rio Doce, 14-IX-1997, *J.A. Lombardi 1995 (MBM); Monte Azul, Serra do Espinhaço, 18-IV-1996, G. Hatschbach 64965 et al. (MBM). L. coulonioides - BRASIL. EsPíRITO SANTO: M. Freire, 21-VII1982, *G. Hatschbach 45173 (MBM); Rio DE JANEIRO: Miguel Pereira, 23/VI/1978, L.F. Aguiar 20 (GUA); Rio de Janeiro, P.N. da Tijuca, 24-VI-1983, M.B. Casari 1021 \& D.S. Pedrosa 918(GUA); São Paulo: São Paulo, VIII-1941, W. Hoehne 692 (SPF); São Paulo, 16-VII-1949, W. Hoehne 3183 (SPF). L. decumbens - BRASIL. Minas GERAIs: Araporanga, Parque Estadual da Serra do Brigadeiro, 27-VIII-2003, G.E. Valente 1287 \& R.M.S.A. Meira (VIC). L. eriolepsis - BRASIL. MinAS Gerais: Passa Quatro, Pinheirinhos, 11-VII-1979, *S. Nunes 149 (RB); Urubus, Pedro Leopoldo, 24-VI-1956, L. Roth 1814 (CESJ); Pedra Branca, 26-X-2002, G. Hatschbach et al. 14523 (VIC); Rio DE JANEIRO: Rio de Janeiro, Tijuca, 14-VIII-1988, R. Esteves \& V. Esteves 308 (R). L. gnaphalioides - BRASIL. MinAs GERAIs: Itacolomi, 7-IV-1973, *Badini s.n. (RB288568); Rio DE JANEIRO: Itatiaia, 2-VIII-1945, A.C. Brade 17407 (RB). L. gracilis - BRASIL. MinAS GERAIS: BR 4 entre km 838-839, 15-I-1965, G. Pabst 8308 \& E. Pereira 9417 (R). L. helophila - BRASIL. São Paulo: São Paulo, Indianópolis, 2-III-1949, *W. Hoehne 3025 (RB); São Paulo, Jaraguá, s.d., W. Hoehne 1095 (RB). L. lilacina - BRASIL. Minas GeraIs: Conceição do Mato Dentro, 18-V-1989, G. Hatschbach 52880 \& V. Nicolack (MBM); Diamantina, 15-III-1970, *H.S. Jeroin et al. 27550 (MBM); Mendanha, 14-IV-1973, W.R. Anderson 8920 (MBM). L. macahensis - BRASIL. RIO DE JANEIRO: Nova Friburgo, Macaé de Cima, 17-VII-1987, S.V.A. Pessoa 237(RB); Macaé de Cima, Picada para a Pedra Bicuda, 19-VIII-1990, M. Leitran 412 (RB); Santa Maria Madalena, 28-VI-1989, G. Martinelli 13353 (RB). L. muricata - BRASIL. EsPíRITO
SANTO: Conceição do Castelo, 20-VIII-1987, G. Hatschbach 51337 \& A.C. Cervi (MBM); Minas Gerais: Gouveia, 24-VIII-1998, *G. Hatschbach et al. 68211 (MBM); Leopoldina, 11-V-1973, P.L. Krieger 13018 (MBM); RIO DE JANEIRO: Volta Redonda, Floresta da Cicuta, 5-V-1992, J.P.P. Carauta 6507 \& D.F. Lima 342 (GUA). L. obtusifolia BRASIL. Rio DE JANEIRO: Rio de Janeiro, Praia do Arpoador, 22-II-1940, Cuezzo 4060 (R); Marambaia, 30-I-1992, D. Araújo 9535 (GUA); Recreio dos Bandeirantes, 21-IV-1965, J.P. Lanna-Sobrinho s.n. (GUA6043); idem, 9-I-1949, *Palácios et al., (R); idem, 22-II-1940, C. Curtiss 26 (R). L. psilostachya - BRASIL. Minas Gerais: São Roque de Minas, P.A.R.N.A., Serra da Canastra, 16-IV-1994, *R. Romero et al. 853 (R); São Paulo: São Paulo, XII-1949, J. Vidal 297 (R). L. remotiflora - BRASIL. MINAS GERAIS: Belo Horizonte, Serra do Curral, 9-IV-1955, L. Roth 1423 (CESJ); Buenópolis, 17-V-2001, G. Hatschbach et al. 72145 (MBM); Uberlândia, 30-V-2003, *A.A.A. Barbosa s.n. (HUFU32819). L. salzmannii - BRASIL. Minas Gerais: São João Del Rey, III-1970, *L. Krieger 8284 (MBM); Viçosa, 12-V-1964, W.N. Vidal 189 (MBM); Rio De Janeiro: Rio de Janeiro, Baixada de Jacarepaguá, entre o Novo Leblon e Malibu, a margem da Lagoa de Marapendi, 18-IV-1998, D.S. Pedrosa 1272 et al. (GUA); Baixada de Jacarepaguá na Reserva Biológica, 20-VII-1977, M.C. Vianna 1090 (GUA); Serra da Estrela, 23-VI-1929, A.C. Brade 10443 (R). L. sericea - BRASIL. Rio DE JANEIRO: Rio de Janeiro, Morro do Leme na orla da floresta, 7-V-1988, J.P.P. Carauta 5566 (GUA); Morro da Urca, 9-VI-1957, L. Duarte s.n. (R75814); Paracambi, Floresta, 21-V-1991, J.P.P. Carauta 6349 (GUA); Represa de Camorim, Maciço da Pedra Branca, 22-IV-1980, *E.S.F. Rocha 45 (GUA). L. sororia - BRASIL. RIO DE JANEIRO: Cabo Frio, Arraial do Cabo, 1953, F. Segadas-Viana et al. s.n. (R153372); Casemiro de Abreu, Barra de São João, 27-V-1953, F. Segadas-Vianna et al. s.n. (R150087); Maricá, restinga, 30-IV-1989, *V. Esteves \& R. Esteves 385 (R); Minas Gerais: São Roque de Minas, P.A.R.N.A. Serra da Canastra, Estrada para Sacramento, 20-VIII-1994, R. Romero et al. 1135 (R) . L. spixiana - BRASIL. Minas Gerais: Diamantina, Morro dos Cruzeiros, VIII-1949, J. Vidal s.n. (R113441); Jaboticatubas, Serra do Cipó, VII-1949, *J. Vidal s.n. (R113440); Ouro Preto, Morro do Cumbe, 3-VIII-1949, J. Vidal s.n. (R113438). L. subsquarrosa - BRASIL. Espírito SAnto: Cachoeira de Itapemirim, Morro do Sal, 20-V-1984, V.F. Ferreira 3400 (GUA); Minas Gerais: Belo Horizonte, 14-VIII-1972, L.E. Mello-Filho 3329 et al. (R); RIO DE JANEIRo: Angra dos Reis, Ilha Grande, Reserva Biológica Estadual da Praia do Sal, 22-VI-1993, *D. Araújo 9826 (GUA); Baixada de Jacarepaguá, entre o Novo Leblon e Malibu, à margem da Lagoa de Marapendi, 3-VIII-1991, D. Araújo 9392 (GUA). L. vauthieriana - BRASIL. MinAs GERAIs: Diamantina, Jaboticatubas, km 139, 20-V-1974, J. Semir \& A.M. Giulietti 4999 (MBM). Serra do Caraça, 11-VI-1884, *Glaziou $15066(\mathrm{R})$.

Para o estudo sob microscópio de luz o material polínico foi preparado segundo o método acetolítico de Ertdman 
(1952), medidos até sete dias após sua preparação (SalgadoLabouriau 1973), fotografados digitalmente e eletromicrografados. Para a análise em microscopia eletrônica de varredura utilizou-se material polínico não acetolisado. Os grãos de pólen foram espalhados sobre suportes metálicos previamente recobertos por fita de carbono e, em seguida receberam, por cerca de três minutos, uma fina camada de ouro paládio sendo analisados em aparelho JSM-5310 pertencente ao Laboratório de Ultraestrutura Celular Hertha Meyer do Instituto de Biofísica, da Universidade Federal do Rio de Janeiro.

Do material padrão foram mensurados vinte e cinco grãos de pólen em vista equatorial (diâmetro polar $=\mathrm{DP}$ e o diâmetro equatorial $=\mathrm{DE}$ ). Em todas as medidas foram incluídos os espinhos. Tratamentos estatísticos foram efetuados calculando-se a média aritmética $(\bar{x})$; o desvio padrão da média $\left(s_{\bar{x}}\right)$ e o intervalo de confiança a $95 \%$. Para as medidas dos demais caracteres como as do diâmetro equatorial em vista polar (DEVP), lado do apocolpo (LA), aberturas e exina foram calculadas a média aritmética de dez medidas, o mesmo ocorrendo para as medidas dos diâmetros dos grãos de pólen dos materiais de comparação.

A terminologia adotada e as descrições polínicas seguiram os critérios de Punt et al. (1999), levando-se em consideração o tamanho, a forma, o número de aberturas e o padrão de ornamentação da sexina; a denominação da área polar e o tamanho da abertura estão de acordo com a classificação estabelecida por Faegri \& Iversen (1966) para o índice da área polar.

\section{Resultados}

Os táxons de Lepidaploa analisados neste estudo (figuras 1-115) apresentaram grãos de pólen de tamanho médio a grande (tabela 1), isopolares, suboblatos em L. gnaphalioides, L. helophila e L. macahensis, oblato-esferoidais, ou ainda, prolato-esferoidais em L. gracilis e L. muricata (tabela 1), âmbito subtriangular, área polar pequena ou grande (tabela 2), 3-colporados de superfície equinolofada.

Aberturas - 3 cólporos situados na área apertural. Os colpos podem ser longos (L. helophila, L. lilacina, L. macahensis e L. sororia) ou curtos (L. gracilis, L. muricata, L. psilostachya e L. spixiana, largos (L. psilostachya e L. spixiana) ou estreitos (L. gnaphalioides, L. gracilis, L. lilacina e $L$. vauthieriana). As endoaberturas localizadas nas lacunas aperturais são preferencialmente lalongadas, sendo lolongadas em L. coulonioides e L. sororia e circulares em L. aurea e L. barbata (tabela 3). Em vista equatorial as áreas aperturais podem se apresentar de três formas: a) com dois muros transversais individualizando três lacunas ficando a endoabertura na lacuna mediana como em $L$. aurea, L. barbata, L. coulonioides e $L$. spixiana (figuras 10, 15, 107); b) com os dois muros não totalmente fundidos ficando apenas próximos sem individualizar as três lacunas L. argyrotricha, L. cotoneaster, L. eriolepis, L. gnaphalioides, L. gracilis, L. psilostachya, L. remotiflora, L. salzmannii, L. sericea $\mathrm{e}$ L. subsquarrosa (figuras 4, 23, 39, 43, 48, 78, 83, 89, 94, 111); c) sem muros transversais formando uma grande área apertural, como em L. chamissonis, L. decumbens, L. helophila, L. lilacina, L. macahensis, L. muricata, L. obtusifolia, L. sororia e L. vauthieriana (figuras 19-20, 33, 52, 59, 64, 68, 72, 101, 117). Algumas espécies apresentam endoabertura com constricção mediana como em $L$. chamissonis, $L$. decumbens, L. eriolepis, L. helophila, L. lilacina, L. obtusifolia, L. sericea e L. subsquarrosa (figuras 19, $33,39,52,58,72,94,111$ ).

Exina - equinolofada, com lacunas formadas por cristas de formas e tamanhos variados (tetragonais, pentagonais e hexagonais). A quantidade e a posição das lacunas variam resultando em quatro padrões de organização: 1 - grãos de pólen com três lacunas aperturais, seis lacunas abaperturais, seis pares de lacunas paraperturais, seis lacunas interaperturais e duas lacunas polares: L. chamissonis, L. cotoneaster, L. gracilis, L. lilacina, L. macahensis, L. muricata, L. salzmannii, L. vauthieriana (figuras $17,22,45$, 56, 61, 66, 86, 114); 2 - grãos de pólen com três lacunas aperturais, seis lacunas abaperturais, seis pares de lacunas paraperturais, seis lacunas interaperturais, duas lacunas polares e três lacunas equatoriais: L. obtusifolia (figuras 70, 73); 3 - grãos de pólen com três lacunas aperturais, seis lacunas abaperturais, seis pares de lacunas paraperturais, seis lacunas interaperturais e ausência de lacunas polares, o que ocasiona a formação de um "Y" formado pela união dos muros das lacunas interaperturais: L. argyrotricha, L. aurea, L. barbata, L. coulonioides, L. decumbens, L. psilostachya, L. remotiflora, L. sororia e L. spixiana (figuras 2 , 7-8, 12, 27, 31, 32, 76, 81, 98, 105); 4 - grãos de pólen com três lacunas aperturais, seis lacunas abaperturais, seis pares de lacunas paraperturais, seis lacunas interaperturais e ausência de lacunas polares, o que ocasiona a formação de um "Y" formado pela união dos muros (cristas) das lacunas interaperturais e três lacunas equatoriais: L. eriolepis, L. gnaphalioides, L. helophila e L. sericea (figuras 39, 42, 53, 94).

A sexina é espessa, perfurada em toda sua extensão, com espinhos espaçados na parte superior 

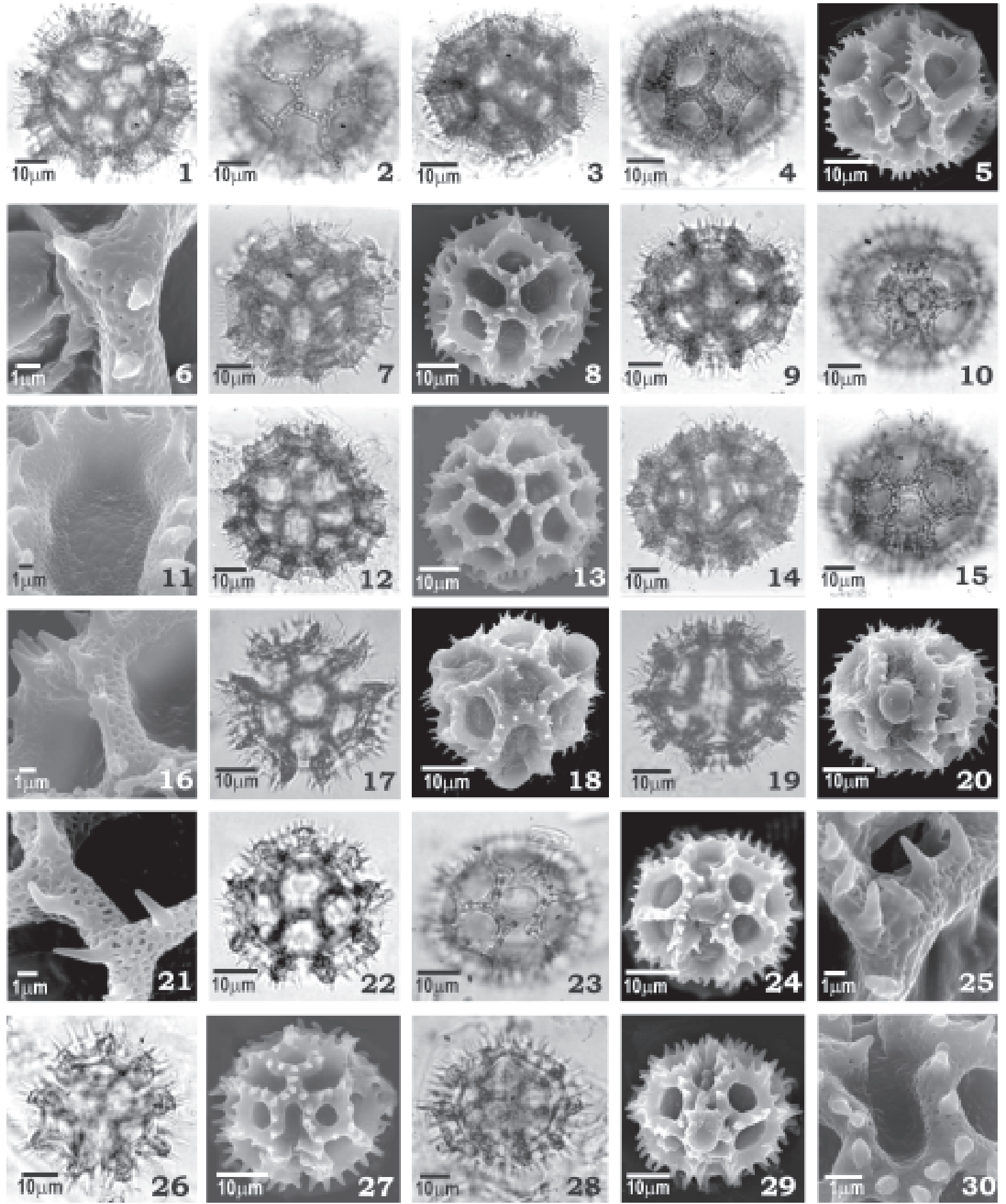

Figuras 1-30. Fotomicrografias $(1-4,7,9-10,12,14-15,17,19,22-23,26,28)$ e eletromicrografias $(5-6,8,11,13,16,18,20-21,24-25$, 27, 29-30) dos grãos de pólen de espécies de Lepidaploa. 1-6. L. argyrotricha. 7-11. L. aurea. 12-16. L. barbata.17-21. L. chamissonis. 22-25. L. cotoneaster. 26-30. L. coulonioides. Vista polar: corte óptico (1, 7, 12, 17, 22, 26); superfície na região do apocolpo $(2,8,13,18,27)$. Vista equatorial: corte óptico $(3,9,14,19,28)$; abertura $(4,5,10,15,20,23,24$, $29)$; detalhe da superfície $(6,11,16,21,25,30)$.

Figures 1-30. LM (1-4, 7, 9-10, 12, 14-15, 17, 19, 22-23, 26, 28) and $\operatorname{SEM}(5-6,8,11,13,16,18,20-21,24-25,27,29-30)$ of Lepidaploa pollen grains. 1-6. L. argyrotricha. 7-11. L. aurea.12-16. L. barbata.17-21. L. chamissonis. 22-25. L. cotoneaster. 26-30. L. coulonioides. Polar view: cross section $(1,7,12,17,22,26)$; surface of apocolpium $(2,8,13,18,27)$. Equatorial view: cross section $(3,9,14,19,28)$; aperture $(4,5,10,15,20,23,24,29)$; detail of surface $(6,11,16,21,25,30)$. 

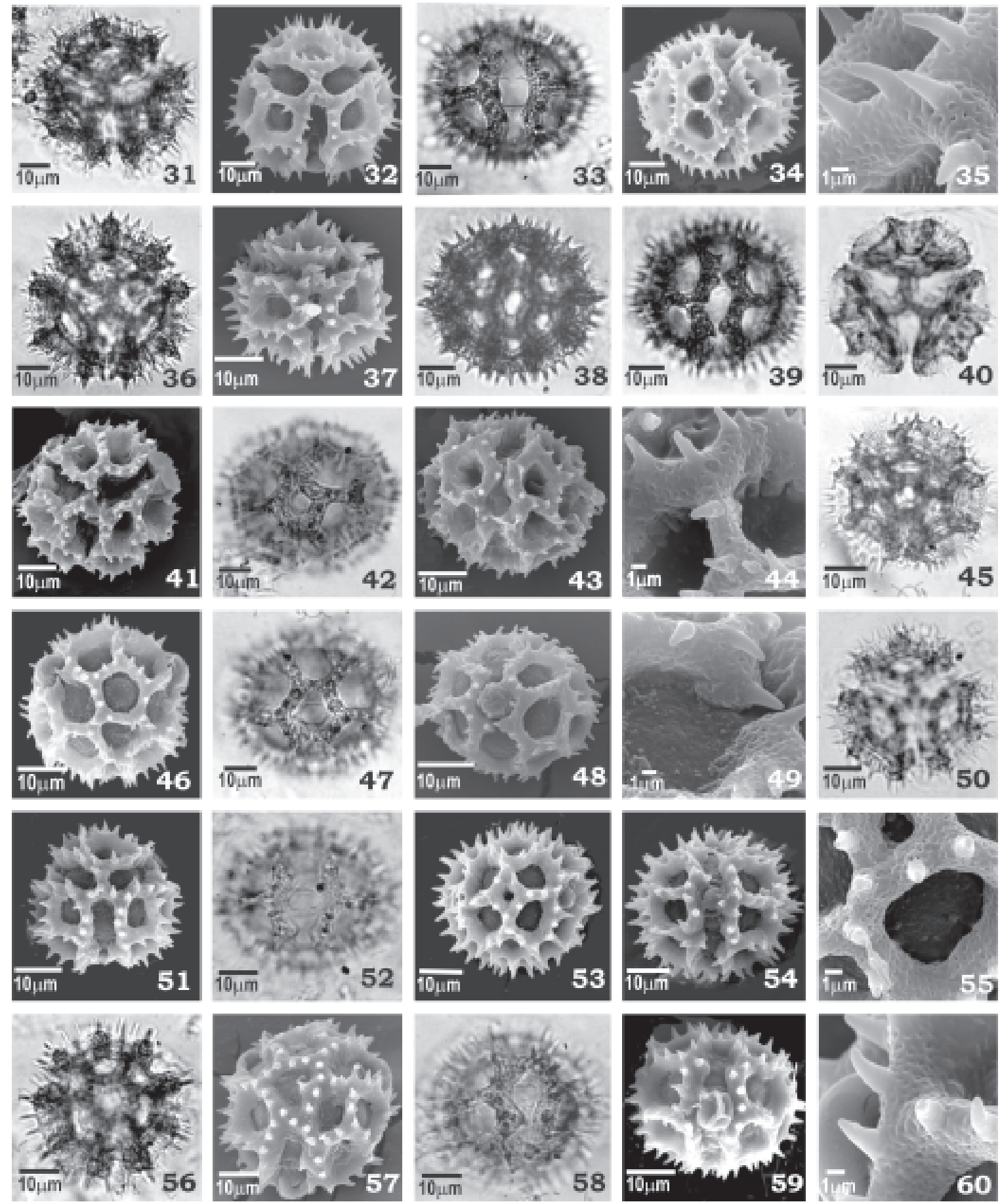

Figuras 31-60. Fotomicrografias (31, 33, 36, 38-40, 42, 45, 47, 50, 52, 56, 58) e eletromicrografias $(32,34-35,37,41,43-44,46,48-49$, 51, 53-55, 57, 59-60) dos grãos de pólen de espécies de Lepidaploa. 31-35. L. decumbens. 36-39. L. eriolepis. 40-44. L. gnaphalioides. 45-49. L. gracilis. 50-55. L. helophila. 56-60. L. lilacina. Vista polar: corte óptico (31, 36, 40, 45, 50, 56); superfície na região do apocolpo (32, 37, 41, 46, 51, 57). Vista equatorial: corte óptico (38); abertura (33, 34, 39, 42, 43, 47, 48, 52, 54, 58, 59); detalhe da superfície (35, 44, 49, 55, 60); mesocolpo (53).

Figures 31-60. LM $(31,33,36,38-40,42,45,47,50,52,56,58)$ and $\operatorname{SEM}(32,34-35,37,41,43-44,46,48-49,51,53-55,57,59-60)$ of Lepidaploa pollen grains. 31-35. L. decumbens. 36-39. L. eriolepis. 40-44. L. gnaphalioides. 45-49. L. gracilis. 50-55. L. helophila. 56-60. L. lilacina. Polar view: cross section (31, 36, 40, 45, 50, 56); surface of apocolpium (32, 37, 41, 46, 51, 57). Equatorial view: cross section (38); aperture $(33,34,39,42,43,47,48,52,54,58,59)$; detail of surface $(35,44,49,55,60)$; mesocolpe (53). 

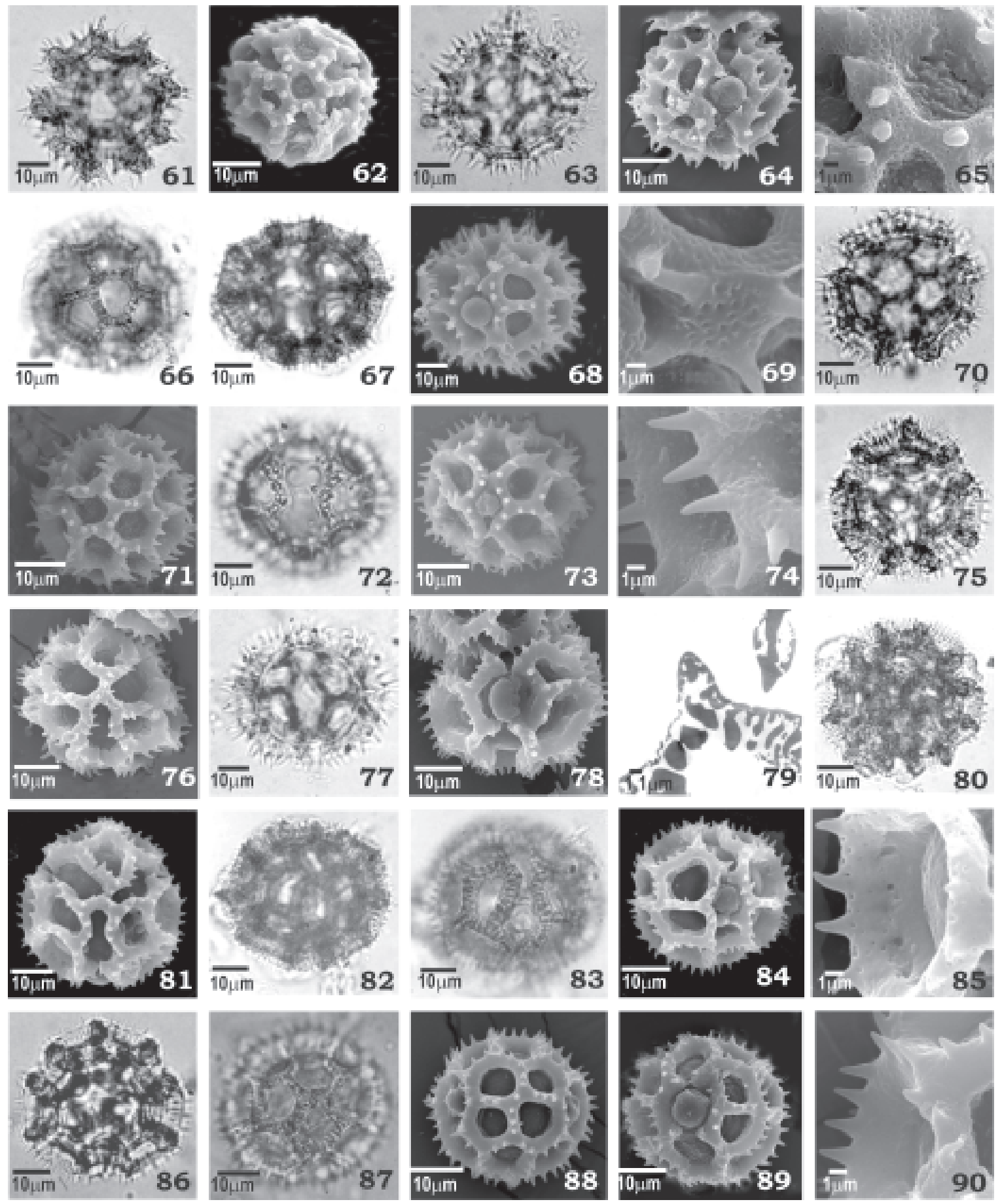

Figuras 61-90. Fotomicrografias $(61,63,66-67,70,72,75,77,80,82-83,86-87)$ e eletromicrografias $(62,64-65,68-69,71,73-74,76$, 78-79, 81, 84-85, 88-90) dos grãos de pólen de espécies de Lepidaploa. 61-65. L. macahensis. 66-69. L. muricata. 70-74. L. obtusifolia. 75-79. L. psilostachya. 80-85. L. remotiflora. 86-90. L. salzmannii. Vista polar: corte óptico $(61,70,75,80,86)$; superfície na região do apocolpo $(62,66,71,76,81)$. Vista equatorial: corte óptico $(63,67,77,82)$; abertura $(64,68,72,73,78,83$, $84,87,89)$; detalhe da superfície $(65,69,74,85,90)$; detalhe da estrutura da exina (79); mesocolpo (88).

Figures 61-90. LM $(61,63,66-67,70,72,75,77,80,82-83,86-87)$ and SEM $(62,64-65,68-69,71,73-74,76,78-79,81,84-85,88-90)$ of Lepidaploa pollen grains. 61-65. L. macahensis. 66-69. L. muricata. 70-74. L. obtusifolia. 75-79. L. psilostachya. 80-85. L. remotiflora. 86-90. L. salzmannii. Polar view: cross section $(61,70,75,80,86)$; surface of apocolpium $(62,66,71,76,81)$. Equatorial view: cross section $(63,67,77,82)$; aperture $(64,68,72,73,78,83,84,87,89)$; detail of surface $(65,69,74,85,90)$; detail of exine (79); mesocolpe (88). 

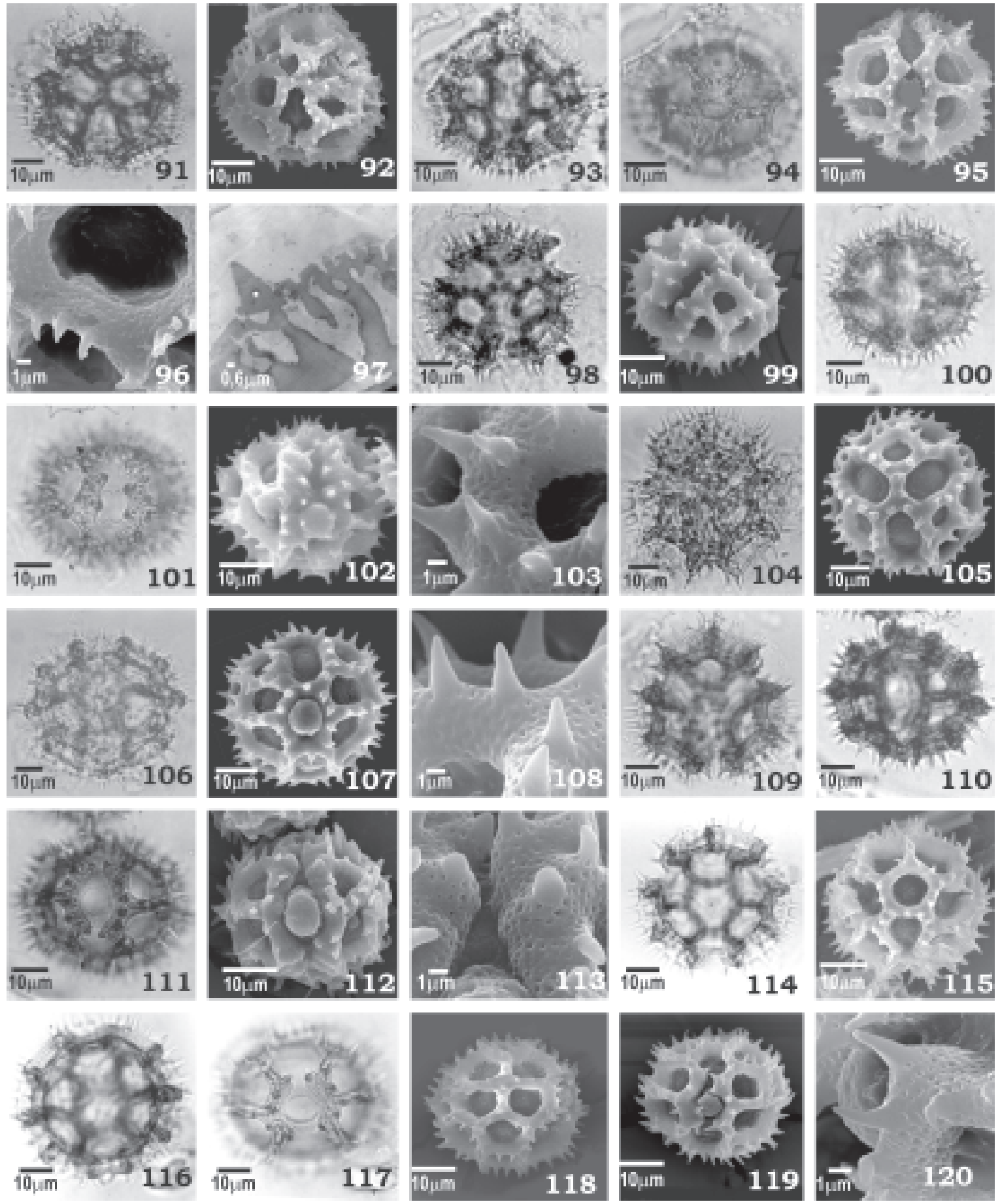

Figuras 91-120. Fotomicrografias (91, 93-94, 98, 100-101, 104, 106, 109-111, 114, 116-117) e eletromicrografias (92, 95-97, 99, 102-103, 105, 107-108, 112-113, 115, 118-120) dos grãos de pólen de espécies de Lepidaploa.91-97. L. sericea. 98-103. L. sororia. 104-108. L. spixiana. 109-113. L. subsquarrosa. 114-120. L. vauthieriana. Vista polar: corte óptico (91, 98, 104, 109, 114); superfície na região do apocolpo $(92,99,105,115)$.Vista equatorial: corte óptico $(93,100,106,110,116)$; abertura $(94,95,101,102$, 107, 111, 112, 117, 119); detalhe da superfície (96, 103, 108, 113, 120); detalhe da estrutura da exina (97); mesocolpo (118).

Figures 91-120. LM(91, 93-94, 98, 100-101, 104, 106, 109-111, 114, 116-117) and SEM(92, 95-97, 99, 102-103, 105, 107-108, 112-113, 115, 118-120) of Lepidaploa pollen grains. 91-97. L. sericea. 98-103. L. sororia. 104-108. L. spixiana. 109-113. L. subsquarrosa. 114-120. L. vauthieriana. Polar view: cross section (91, 98, 104, 109, 114); surface of mesocolpium (92, 99, 105, 115). Equatorial view: cross section $(93,100,106,110,116)$; aperture $(94,95,101,102,107,111,112,117,119)$; detail of surface $(96,103,108,113$, 120); detail of exine (97); mesocolpe (118). 
Tabela 1. Medidas (em $\mu \mathrm{m})$ dos grãos de pólen em vista equatorial $(n=25)$ de espécies de Lepidaploa. $(\bar{x}=$ média aritmética; $s_{\overline{\mathrm{x}}}=$ desvio padrão da amostra; IC = intervalo de confiança; $\mathrm{P}=$ diâmetro polar; $\mathrm{E}=$ diâmetro equatorial $)$.

Table 1. Measures $(\mu \mathrm{m})$ of pollen grains in equatorial view $(n=25)$ of Lepidaploa species. $\left(\bar{x}=\right.$ arithmetic mean; $s_{\overline{\times}}=$ medium standard deviation; $\mathrm{IC}=$ confidence interval; $\mathrm{P}=$ polar diameter; $\mathrm{E}=$ equatorial diameter $)$.

\begin{tabular}{|c|c|c|c|c|c|c|c|}
\hline \multirow[t]{2}{*}{ Espécies } & \multicolumn{3}{|c|}{ Diâmetro polar } & \multicolumn{3}{|c|}{ Diâmetro equatorial } & \multirow[t]{2}{*}{$\mathrm{P} / \mathrm{E}$} \\
\hline & Faixa de variação & $\bar{x} \pm s_{\bar{x}}$ & IC $95 \%$ & Faixa de variação & $\bar{x} \pm s_{\bar{x}}$ & IC $95 \%$ & \\
\hline L. argyrotricha & $48,7-52,5$ & $50,7 \pm 0,3$ & $50,1-51,2$ & $52,5-55,0$ & $53,6 \pm 0,2$ & $53,1-54,0$ & 0,94 \\
\hline L. aurea & $47,5-50,0$ & $49,4 \pm 0,1$ & $49,0-49,7$ & $52,5-55,0$ & $53,6 \pm 0,2$ & $53,1-54,0$ & 0,92 \\
\hline L. barbata & $52,5-58,7$ & $55,2 \pm 0,3$ & $54,5-55,8$ & $52,5-60,0$ & $58,3 \pm 0,4$ & $57,4-59,1$ & 0,94 \\
\hline L. chamissonis & $42,5-45,0$ & $43,3 \pm 0,2$ & $42,8-43,7$ & $45,0-47,5$ & $46,8 \pm 0,2$ & $46,4-47,2$ & 0,92 \\
\hline L. cotoneaster & $37,5-41,2$ & $39,1 \pm 0,3$ & $38,7-39,7$ & $37,5-42,5$ & $40,0 \pm 0,2$ & $40,3-40,7$ & 0,97 \\
\hline L. coulonioides & $42,5-47,5$ & $44,8 \pm 0,3$ & $44,2-45,3$ & $47,5-53,7$ & $50,1 \pm 0,3$ & $49,4-50,8$ & 0,89 \\
\hline L. decumbens & $50,0-52,5$ & $51,3 \pm 0,2$ & $50,8-51,7$ & $55,0-58,7$ & $57,2 \pm 0,2$ & $56,7-57,6$ & 0,89 \\
\hline L. eriolepis & $50,0-53,7$ & $52,1 \pm 0,2$ & $51,6-52,5$ & $56,2-58,7$ & $57,3 \pm 0,1$ & $57,0-57,5$ & 0,90 \\
\hline L. gnaphalioides & $47,5-50,0$ & $48,7 \pm 0,2$ & $48,2-49,2$ & $55,0-58,7$ & $56,9 \pm 0,3$ & $56,3-57,5$ & 0,85 \\
\hline L. gracilis & $40,0-42,5$ & $40,8 \pm 0,2$ & $40,3-41,2$ & $37,5-40,0$ & $38,7 \pm 0,2$ & $38,3-39,1$ & 1,05 \\
\hline L. helophila & $41,2-43,7$ & $42,4 \pm 0,2$ & $42,8-42,7$ & $47,5-50,0$ & $48,4 \pm 0,2$ & $48,0-48,8$ & 0,87 \\
\hline L. lilacina & $42,5-46,2$ & $43,8 \pm 0,2$ & $43,3-44,3$ & $45,0-47,0$ & $46,0 \pm 0,2$ & $45,5-46,4$ & 0,95 \\
\hline L. macahensis & $50,0-52,5$ & $50,4 \pm 0,2$ & $50,1-50,8$ & $57,5-60,0$ & $58,0 \pm 0,2$ & $57,6-58,4$ & 0,86 \\
\hline L. muricata & $42,5-46,2$ & $45,0 \pm 0,3$ & $44,4-45,5$ & $42,5-46,2$ & $43,9 \pm 0,2$ & $43,4-44,3$ & 1,02 \\
\hline L. obtusifolia & $43,7-47,5$ & $45,4 \pm 0,2$ & $44,9-45,8$ & $47,5-51,2$ & $49,4 \pm 0,2$ & $48,9-49,8$ & 0,91 \\
\hline L. psilostachya & $50,0-52,5$ & $51,4 \pm 0,2$ & $50,8-51,9$ & $52,5-56,2$ & $53,3 \pm 0,2$ & $52,8-53,7$ & 0,96 \\
\hline L. remotiflora & $42,5-46,2$ & $44,4 \pm 0,3$ & $43,8-44,9$ & $47,5-51,2$ & $49,5 \pm 0,2$ & $49,0-50,0$ & 0,89 \\
\hline L. salzmannii & $41,2-43,7$ & $42,0 \pm 0,1$ & $41,7-42,2$ & $45,0-46,2$ & $45,2 \pm 0,1$ & $45,0-45,4$ & 0,99 \\
\hline L. sericea & $47,5-51,7$ & $49,2 \pm 0,3$ & $48,6-49,8$ & $52,5-55,0$ & $54,1 \pm 02$ & $53,7-55,0$ & 0,90 \\
\hline L. sororia & $40,0-45,0$ & $42,9 \pm 0,2$ & $42,4-43,4$ & $46,2-50,0$ & $48,0 \pm 0,2$ & $47,5-48,5$ & 0,89 \\
\hline L. spixiana & $57,5-61,2$ & $58,9 \pm 0,2$ & $58,3-59,4$ & $62,5-65,0$ & $63,3 \pm 0,2$ & $62,9-63,7$ & 0,93 \\
\hline L. subsquarrosa & $45,0-47,5$ & $46,5 \pm 0,1$ & $46,1-46,8$ & $50,0-53,7$ & $52,1 \pm 0,2$ & $51,6-52,6$ & 0,89 \\
\hline L. vauthieriana & $45,0-47,5$ & $46,4 \pm 0,2$ & $46,0-46,8$ & $50,0-53,7$ & $51,7 \pm 0,2$ & $51,2-52,1$ & 0,89 \\
\hline
\end{tabular}

dos muros. O comprimento e a largura dos espinhos, bem como a distância entre eles varia nas espécies. Assim, os espinhos mais compridos são encontrados em L. lilacina, L. obtusifolia e L. salzmannii e os mais curtos, em L. gnaphalioides, L. muricata e L. remotiflora. A largura dos espinhos não apresenta variação significativa na maioria das espécies, ficando os valores na faixa de 1,0-2,0 $\mu$ m (tabela 3). Em relação à distância entre os espinhos, os valores ficam situados na faixa de $2,3 \mu \mathrm{m}$ (em L. remotiflora) a $5,7 \mu \mathrm{m}$ (L. macahensis). A nexina é sempre menos espessa do que a sexina (tabela 3 ).

A tabela 5 mostra que os resultados encontrados nos espécimes de comparação apresentam os valores dos diâmetros polar e equatorial, em sua maioria, dentro dos limites da faixa de variação quando comparados com o respectivo material padrão exceto para L. argyrotricha (J. Vidal s.n.), L. subsquarrosa (D. Araujo 9392), L. cotoneaster (G. Hatschbach 64965), L. barbata (L. Netto s.n.) e L. salzmannii (A.C. Brade 10443, W.N. Vidal 189) que encontram-se fora da faixa de variação do material padrão. A média da maioria do material de comparação está fora do intervalo de confiança do material padrão. Quanto à forma, verificar que os materiais L. helophila (W. Hoehne 1095) e L. macahensis (M. Leiran 412) estão de acordo com material padrão, conforme glossário Punt et al. (1999) e Barth \& Melhem (1988). Quanto à forma, apenas L. coulonioides (M.B. Casari 1021 \& D.S. Pedrosa 918) e L. muricata (J.P.P. Carauta 6507 \& D.F. Lima 342) mostram-se diferentes do material padrão (tabelas 1, 5). 
Tabela 2. Medidas (em $\mu \mathrm{m})$ dos grãos de pólen em vista polar de espécies de Lepidaploa $(n=10)$. (DEVP= diâmetro equatorial; LA = lado do apocolpo; IAP = índice da área polar).

Table 2. Measures $(\mu \mathrm{m})$ of pollen grains in polar view of Lepidaploa species $(n=10)$. (DEVP = equatorial diameter; $\mathrm{LA}=$ apocolpium side; IAP = polar area index $)$.

\begin{tabular}{|c|c|c|c|c|c|c|}
\hline \multirow[t]{2}{*}{ Espécies } & \multicolumn{2}{|c|}{ Diâmetro equatorial } & \multicolumn{3}{|c|}{ LA } & \multirow{2}{*}{$\begin{array}{l}\text { Área polar } \\
\text { LA/DEVP }\end{array}$} \\
\hline & Faixa de variação & $\bar{x}$ & Faixa de variação & $\bar{x}$ & IAP & \\
\hline L. argyrotricha & $52,5-56,2$ & 53,6 & $28,7-31,2$ & 30,0 & 0,55 & grande \\
\hline L. aurea & $50,0-52,5$ & 51,7 & $17,5-20,0$ & 18,6 & 0,35 & pequena \\
\hline L. barbata & $55,0-60,0$ & 56,4 & $32,5-35,0$ & 33,6 & 0,59 & grande \\
\hline L. chamissonis & $43,7-46,2$ & 44,8 & $17,5-20,0$ & 18,4 & 0,41 & pequena \\
\hline L. cotoneaster & $37,5-42,5$ & 40,1 & $22,5-26,2$ & 24,5 & 0,61 & grande \\
\hline L. coulonioides & $47,5-53,7$ & 49,8 & $25,0-28,7$ & 27,0 & 0,54 & grande \\
\hline L. decumbens & $57,5-60,0$ & 58,7 & $25,0-27,5$ & 25,5 & 0,43 & pequena \\
\hline L. eriolepis & $56,2-57,5$ & 57,1 & $20,0-25,0$ & 22,5 & 0,39 & pequena \\
\hline L. gnaphalioides & $52,5-56,2$ & 54,5 & $20,0-25,0$ & 22,1 & 0,40 & pequena \\
\hline L. gracilis & $38,7-41,2$ & 40,2 & $21,2-23,7$ & 23,0 & 0,57 & grande \\
\hline L. helophila & $45,0-47,5$ & 47,0 & $17,5-12,5$ & 14,5 & 0,30 & pequena \\
\hline L. lilacina & $42,5-46,2$ & 45,2 & $22,5-23,7$ & 23,1 & 0,51 & grande \\
\hline L. macahensis & $55,0-57,5$ & 56,0 & $17,5-20,0$ & 18,7 & 0,34 & pequena \\
\hline L. muricata & $42,5-46,2$ & 44,3 & $26,2-28,7$ & 27,1 & 0,61 & grande \\
\hline L. obtusifolia & $46,2-50,0$ & 48,2 & $18,7-22,5$ & 20,1 & 0,41 & pequena \\
\hline L. psilostachya & $50,0-52,5$ & 51,8 & $26,2-30,0$ & 28,3 & 0,54 & grande \\
\hline L. remotiflora & $45,0-50,0$ & 48,2 & $15,0-17,5$ & 16,7 & 0,34 & pequena \\
\hline L. salzmannii & $45,0-47,5$ & 46,5 & $12,5-15,0$ & 14,1 & 0,30 & pequena \\
\hline L. sericea & $50,0-52,5$ & 51,2 & $22,5-25,0$ & 23,5 & 0,45 & pequena \\
\hline L. sororia & $46,2-47,5$ & 47,3 & $25,0-31,2$ & 25,7 & 0,54 & grande \\
\hline L. spixiana & $60,0-65,0$ & 61,5 & $25,0-30,0$ & 26,1 & 0,42 & pequena \\
\hline L. subsquarrosa & $51,2-53,7$ & 52,1 & $22,5-25,0$ & 24,0 & 0,46 & pequena \\
\hline L vauthieriana & $50,0-52,5$ & 50,7 & $20,0-22,5$ & 20,7 & 0,40 & pequena \\
\hline
\end{tabular}

Chave polínica para separação das espécies de Lepidaploa

1. Grãos de pólen com duas lacunas polares, três lacunas aperturais, seis lacunas abaperturais, seis pares de lacunas paraperturais, seis lacunas interaperturais, com ou sem lacunas equatoriais

2. Grãos de pólen com lacuna equatorial L. obtusifolia

2. Grãos de pólen sem lacuna equatorial

3. Área apertural com dois muros não totalmente individualizados em três lacunas

4. Grãos de pólen prolato-esferoidais

L. gracilis

4. Grãos de pólen oblato-esferoidais

5. Grãos de pólen com área polar pequena, endoabertura nitidamente lalongada ......... L. salzmannii

5. Grãos de pólen com área polar grande, endoabertura \pm circular

L.cotoneaster

3. Área apertural sem muros transversais individualizando as lacunas

6. Grãos de pólen grandes, suboblatos

L. macahensis

6. Grãos de pólen médios, oblato-esferoidais ou prolato-esferoidais

7. Grãos de pólen prolato-esferoidais

L. muricata

7. Grãos de pólen oblato-esferoidais

8. Área polar grande, compr. do colpo $>26,0 \mu \mathrm{m}$, compr. do espinho $>5,0 \mu \mathrm{m}$

L. lilacina

8. Área polar pequena, compr. do colpo $\leq 18,6 \mu \mathrm{m}$, compr. do espinho $\leq 4,0 \mu \mathrm{m}$ 
9. Compr. do espinho ca. 2,9 mm, endoabertura com constricção mediana, DP $(\mathrm{IC}=42,8-43,7 \mu \mathrm{m})$ L. chamissonis

9. Compr. do espinho ca. 4,0 mm, endoabertura sem constricção mediana, DP $(\mathrm{IC}=46,0-46,8 \mu \mathrm{m})$

L. vauthieriana

1. Grãos de pólen sem lacuna polar, três lacunas aperturais, seis lacunas abaperturais, seis pares de lacunas paraperturais, seis lacunas interaperturais, ausência de lacunas polares, com ou sem lacunas equatoriais

10. Grãos de pólen sem lacuna equatorial

11. Área apertural grande, sem muros transversais

12. Grãos de pólen grandes, DP $(\mathrm{IC}=50,8-51,7 \mu \mathrm{m})$ L. decumbens

12. Grãos de pólens médios, DP ( $\mathrm{IC}<50,0 \mu \mathrm{m})$

13. Grãos de pólen com área polar grande, compr. do colpo $c a .25,8 \mu \mathrm{m}$, endoabertura lolongada, sem constricção mediana L. sororia

13. Grãos de pólen com área polar pequena, compr. do colpo $c a$. 17,4 $\mu \mathrm{m}$, endoabertura lalongada, com constricção mediana L. subsquarrosa

11. Área apertural com dois muros individualizando ou não as três lacunas

14. Área apertural com dois muros totalmente individualizados em três lacunas

15. Grãos de pólens grandes, DP (IC > 54,0 $\mu \mathrm{m}$ )

16. Grãos de pólen com área polar grande, compr. do colpo ca. 16,7 $\mu \mathrm{m}$, endoabertura circular, $\mathrm{DP}(\mathrm{IC}=54,5-55,8 \mu \mathrm{m})$

L. barbata

16. Grãos de pólen com área polar pequena, compr. do colpo ca. 14,2 $\mu \mathrm{m}$, endoabertura nitidamente lalongada, $\mathrm{DP}(\mathrm{IC}=58,3-59,4 \mu \mathrm{m})$

L. spixiana

15. Grãos de pólen médios, DP (IC $<50,0 \mu \mathrm{m})$

17. Grãos de pólen com área polar grande, compr. do colpo ca. 21,7 $\mu \mathrm{m}$, endoabertura nitidamente lolongada, DP (IC $=44,2-45,3 \mu \mathrm{m})$ L. coulonioides

17. Grãos de pólen com área polar pequena, compr. do colpo $c a .12,3 \mu \mathrm{m}$, endoabertura circular, DP $(\mathrm{IC}=49,0-49,7 \mu \mathrm{m})$ L. aurea

14. Área apertural com dois muros não totalmente individualizados em três lacunas

18. Grãos de pólen médios, área polar pequena, compr. do colpo ca. 22,0 $\mu \mathrm{m}$, compr. do espinho $c a$. de $2,5 \mu \mathrm{m}$ L. remotiflora

18. Grãos de pólen grandes, área polar grande, compr. do colpo $<17,0 \mu \mathrm{m}$, compr. do espinho $\geq 3,5 \mu \mathrm{m}$

19. Compr. do colpo $c a$. 16,7 $\mu \mathrm{m}$, endoabertura \pm circular, compr. do espinho $c a$. $4,0 \mu \mathrm{m}$ L. argyrotricha

19. Compr. do colpo $c a$. 12,0 $\mu \mathrm{m}$, endoabertura nitidamente lalongada, compr. do espinho $c a .3,5 \mu \mathrm{m}$ L. psilostachya

10. Grãos de pólen com três lacunas aperturais, seis lacunas abaperturais, seis pares de lacunas paraperturais, seis lacunas interaperturais, ausência de lacunas polares, com lacunas equatoriais 20. Área apertural grande, sem muros transversais (lacuna apertural do tipo c), DP (IC $=42,0$ $42,8 \mu \mathrm{m}$ L. heliofila

20. Área apertural com dois muros não totalmente individualizados em três lacunas, DP (IC > $48,0 \mu \mathrm{m})$

21. Grãos de pólen grandes, $\mathrm{DP}(\mathrm{IC}=51,6-52,5 \mu \mathrm{m})$ L. eriolepis

21. Grãos de pólen médios, DP (IC > 48,0 $\mu \mathrm{m}$ )

22. Grãos de pólen suboblatos, compr. do colpo $c a$. 19,0 $\mu \mathrm{m}$, endoabertura lalongada sem constricção mediana, compr. do espinho $c a .2,2 \mu \mathrm{m}$ L. gnaphalioides

22. Grãos de pólen oblato-esferoidais, compr. do colpo $c a$. 21,5 $\mu \mathrm{m}$, endoabertura nitidamente lalongada com constricção mediana, compr. do espinho $c a .3,7 \mu \mathrm{m}$ L. sericea 
Tabela 3. Média aritmética $(\mu \mathrm{m})$ das medidas das aberturas, das camadas da exina e dos espinhos dos grãos de pólen das espécies de Lepidaploa $(n=10)$. (compr. = comprimento; larg. = largura).

Table 3. Arithmetic mean $(\mu \mathrm{m})$ of the apertures, and morphometric data of pollen grains exine and spines of Lepidaploa species $(n=10)$. (compr. = length; larg. = width).

\begin{tabular}{|c|c|c|c|c|c|c|c|c|c|c|}
\hline \multirow[t]{2}{*}{ Espécies } & \multicolumn{2}{|c|}{ Colpo } & \multicolumn{2}{|c|}{ Endoabertura } & \multicolumn{3}{|c|}{ Espessura da exina } & \multicolumn{3}{|c|}{ Espinhos } \\
\hline & compr. & larg. & compr. & larg. & exina total & sexina & nexina & distância & compr. & larg. \\
\hline L. argyrotricha & 16,7 & 7,5 & 7,5 & 7,7 & 10,9 & 9,9 & 1,0 & 3,9 & 4,0 & 1,2 \\
\hline L. aurea & 12,3 & 7,8 & 7,0 & 7,0 & 9,6 & 8,6 & 1,0 & 3,5 & 3,7 & 1,1 \\
\hline L. barbata & 16,7 & 9,1 & 10,4 & 10,4 & 10,2 & 9,0 & 1,2 & 4,3 & 3,0 & 1,0 \\
\hline L. chamissonis & 17,6 & 7,1 & 6,5 & 9,8 & 8,7 & 7,7 & 1,0 & 3,0 & 2,9 & 1,0 \\
\hline L. cotoneaster & 18,0 & 6,5 & 8,0 & 8,2 & 7,9 & 6,9 & 1,0 & 3,2 & 3,0 & 1,0 \\
\hline L. coulonioides & 21,7 & 7,0 & 8,2 & 7,5 & 10,5 & 9,5 & 1,0 & 5,3 & 4,2 & 2,0 \\
\hline L. decumbens & 20,4 & 8,4 & 7,5 & 9,0 & 10,5 & 9,5 & 1,0 & 4,9 & 4,1 & 1,1 \\
\hline L. eriolepis & 21,5 & 6,7 & 8,4 & 9,2 & 11,4 & 10,4 & 1,0 & 5,3 & 4,0 & 1,2 \\
\hline L. gnaphalioides & 19,0 & 5,0 & 7,0 & 8,0 & 11,0 & 10,0 & 1,0 & 4,5 & 2,2 & 1,0 \\
\hline L. gracilis & 15,0 & 5,0 & 4,6 & 7,8 & 8,6 & 7,6 & 1,0 & 3,9 & 3,4 & 1,1 \\
\hline L. helophila & 25,0 & 7,2 & 6,5 & 8,8 & 9,5 & 8,5 & 1,0 & 4,3 & 4,0 & 1,1 \\
\hline L. lilacina & 26,8 & 4,9 & 6,5 & 7,7 & 10,4 & 9,4 & 1,0 & 5,0 & 5,5 & 1,0 \\
\hline L. macahensis & 26,0 & 6,5 & 6,5 & 9,0 & 9,0 & 8,0 & 1,0 & 5,7 & 3,7 & 1,5 \\
\hline L. muricata & 15,3 & 9,4 & 6,2 & 7,3 & 9,3 & 8,3 & 1,0 & 2,8 & 2,5 & 1,0 \\
\hline L. obtusifolia & 18,0 & 6,5 & 5,5 & 8,5 & 10,6 & 9,6 & 1,0 & 4,2 & 5,0 & 1,1 \\
\hline L. psilostachya & 12,0 & 10,0 & 6,0 & 9,0 & 11,6 & 10,5 & 1,1 & 3,2 & 3,5 & 1,0 \\
\hline L. remotiflora & 22,0 & 5,0 & 6,0 & 7,0 & 7,9 & 6,9 & 1,0 & 2,3 & 2,5 & 1,0 \\
\hline L. salzmannii & 22,0 & 6,5 & 6,4 & 7,4 & 13,4 & 12,3 & 1,1 & 5,4 & 5,4 & 1,1 \\
\hline L. sericea & 21,5 & 9,5 & 7,8 & 11,7 & 11,6 & 10,6 & 1,0 & 4,3 & 3,7 & 1,1 \\
\hline L. sororia & 25,8 & 5,2 & 9,1 & 6,6 & 9,7 & 8,7 & 1,0 & 3,5 & 3,7 & 1,0 \\
\hline L. spixiana & 14,2 & 10,8 & 8,0 & 9,2 & 11,8 & 10,8 & 1,0 & 5,3 & 4,4 & 1,6 \\
\hline L. subsquarrosa & 17,4 & 8,4 & 6,4 & 9,0 & 10,8 & 9,8 & 1,0 & 4,7 & 4,0 & 1,4 \\
\hline L. vauthieriana & 18,6 & 4,2 & 6,5 & 8,1 & 9,6 & 8,5 & 1,0 & 4,3 & 4,0 & 1,0 \\
\hline
\end{tabular}

\section{Discussão}

As 23 espécies de Lepidaploa aqui estudadas possuem grãos de pólen equinolofados apresentando diferenças nas características morfopolínicas, principalmente, relacionadas aos padrões de organização e tipos de lacunas, bem como no tamanho e na forma como pode ser evidenciado na chave polínica aqui construída.

As espécies foram separadas na chave polínica, primeiramente, em dois grandes grupos: com ou sem lacuna polar. No primeiro grupo foram reunidos nove táxons e no segundo, o maior deles, 14 táxons. Estes grupos foram subdivididos, por sua vez, pela presença ou não de lacuna equatorial e forma da área apertural. Os grãos de pólen de Lepidaploa obtusifolia (incluídos no primeiro grupo) separaram-se de todas as outras espécies estudadas pela presença de lacuna polar e lacuna equatorial enquanto que os de L. helophila (incluídos no segundo grupo) formaram um subgrupo juntamente com L. eriolepis, L. gnaphalioides e L. sericea por apresentarem lacuna equatorial e exina com padrão de organização 4. Os grãos de pólen de L. heliofila se separaram dos demais deste subgrupo por possuírem área apertural grande e ausência de muros transversais (lacuna apertural tipo c).

Stix (1960), ao estudar 225 espécies sob microscopia de luz e eletrônica de transmissão, criou 42 tipos polínicos para a família com base na observação da ornamentação e estrutura da exina. O autor apresentou, para o tipo Vernonia, três diagramas com grãos de pólen lofados abertos, classificando a lacuna de acordo com a sua posição em relação à abertura. Comparando esses diagramas com os tipos polínicos encontrados no presente estudo pôde-se enquadrar as espécies: L. aurea, L. barbata, L. coulonioides, L. spixiana no tipo "Vernonia arenaria"; L. chamissonis, L. cotoneaster, L. gracilis, L. lilacina, 
Tabela 4. Número de lacunas presentes nos grãos de pólen de Lepidaploa

Table 4. Lacunae number in Lepidaploa pollen grains.

\begin{tabular}{lccccccc}
\hline Espécies & Abapertural & Interapertural & Polar & Apertural & Parapertural & Equatorial & Total \\
\hline L. argyrotricha & 6 & 6 & - & 3 & 12 & - & 27 \\
L. aurea & 6 & 6 & - & 3 & 12 & - & 27 \\
L. barbata & 6 & 6 & - & 3 & 12 & - & 27 \\
L. chamissonis & 6 & 6 & 2 & 3 & 12 & - & 29 \\
L. cotoneaster & 6 & 6 & 2 & 3 & 12 & - & 29 \\
L. coulonioides & 6 & 6 & - & 3 & 12 & - & 27 \\
L. decumbens & 6 & 6 & - & 3 & 12 & - & 27 \\
L. eriolepis & 6 & 6 & - & 3 & 12 & 3 & 30 \\
L. gnaphalioides & 6 & 6 & - & 3 & 12 & 3 & 30 \\
L. gracilis & 6 & 6 & 2 & 3 & 12 & - & 29 \\
L. helophila & 6 & 6 & - & 3 & 12 & 3 & 30 \\
L. lilacina & 6 & 6 & 2 & 3 & 12 & - & 29 \\
L. macahensis & 6 & 6 & 2 & 3 & 12 & - & 29 \\
L. muricata & 6 & 6 & 2 & 3 & 12 & - & 29 \\
L. obtusifolia & 6 & 6 & 2 & 3 & 12 & 3 & 32 \\
L. psilostachya & 6 & 6 & - & 3 & 12 & - & 27 \\
L. remotiflora & 6 & 6 & - & 3 & 12 & - & 27 \\
L. salzmannii & 6 & 6 & 2 & 3 & 12 & - & 29 \\
L. sericea & 6 & 6 & - & 3 & 12 & 3 & 30 \\
L. sororia & 6 & 6 & - & 3 & 12 & - & 27 \\
L. spixiana & 6 & 6 & - & 3 & 12 & - & 27 \\
L. subsquarrosa & 6 & 6 & - & 3 & 12 & - & 27 \\
L. vauthieriana & 6 & 6 & 2 & 3 & 12 & - & 29 \\
\hline
\end{tabular}

L. macahensis, L. muricata, L. salzmannii e L. vauthieriana no tipo "Vernonia cognata"; L. heliofila, L. eriolepsis, L. gnaphalioides e L. sericea no tipo "Vernonia argyrophylla". As demais espécies aqui analisadas não se enquadram nos outros tipos polínicos de Vernonia Schreb. criados por Stix (1960).

Kingham (1976) estabeleceu seis tipos polínicos com base no padrão de lacunas da exina e três subtipos pela forma da lacuna apertural. Confrontando os resultados aqui obtidos com os do referido autor verificou-se que todas as espécies aqui estudadas enquadraram-se no tipo IV por ele apresentado. $\mathrm{Na}$ descrição desse tipo, o autor não faz menção à presença de lacuna equatorial embora a figura que ilustre o tipo mostre a existência desta lacuna. Todos os táxons aqui estudados puderam ser enquadrados nos subtipos apresentados por Kingham (1976), predominando o subtipo b.

Kelley \& Jones (1977) criaram três tipos polínicos (A, B e C) baseando-se na observação da ornamentação e comprimento dos espinhos, para o gênero Vernonia ocorrente nas Antilhas. Posteriormente, Jones (1979) apresentou a descrição do quarto tipo polínico (D) para as Vernonia do Novo Mundo. Na caracterização desses tipos polínicos os autores não fazem referência à existência ou não de lacuna equatorial. Assim, com base nas descrições desses autores, considerando apenas a presença ou não de lacuna polar, os grãos de pólen das espécies aqui estudadas enquadram-se melhor nos tipos B (14 espécies) e C (com nove espécies).

Nair \& Lawrence (1985) estudaram as Compositae da Flora Indiana analisando grãos de pólen de várias tribos e, dentre elas, Vernonieae com vinte e cinco espécies. As autoras fizeram considerações sobre grãos de pólen lofados utilizando termos, tais como "ilhas nodais", "ilhas de muros simples", "mega-ilhas" e "micro-ilhas" para descrever as variações na ornamentação do padrão lofado. No presente estudo, essas denominações foram consideradas impróprias, pois na realidade, representam os níveis de focalização dos espinhos ("ilha nodal", "ilha internodal" e "mega-ilha") e as perfurações aqui observadas foram denominadas pelas autoras de "micro-ilhas". 
Tabela 5. Medidas $(e m \mu \mathrm{m})$ dos grãos de pólen dos materiais de comparação $(n=10)$ de espécies de Lepidaploa. $(\mathrm{P}=$ diâmetro polar; $\mathrm{E}$ = diâmetro equatorial; $\mathrm{DEVP}$ = diâmetro equatorial em vista polar; $\mathrm{LA}$ = lado do apocolpo; IAP = índice da área polar).

Table 5. Measures $(\mu \mathrm{m})$ of pollen grains of comparison material $(n=10)$ Lepidaploa species. $(\mathrm{P}=$ polar diameter; $\mathrm{E}=$ equatorial diameter; DEVP = equatorial diameter; LA = apocolpium side; IAP = polar area index).

\begin{tabular}{|c|c|c|c|c|c|c|c|}
\hline Espécimens & $\begin{array}{l}\text { Diâmetro } \\
\text { polar } \\
\bar{x}\end{array}$ & $\begin{array}{c}\text { Diâmetro } \\
\text { equatorial } \\
\bar{x}\end{array}$ & $\mathrm{P} / \mathrm{E}$ & Forma & DEVP & $\bar{x}$ & IAP \\
\hline \multicolumn{8}{|l|}{ L. argyrotricha } \\
\hline J. Vidal s.n. & 45,9 & 50,2 & 0,91 & oblato-esferoidal & 51,9 & 29,6 & 0,57 \\
\hline E. Giannotti et al. & 50,3 & 52,8 & 0,95 & oblato-esferoidal & 52,6 & 28,9 & 0,54 \\
\hline G. Hatschbach et. al. 72105 & 49,7 & 52,8 & 0,94 & oblato-esferoidal & 53,1 & 28,8 & 0,54 \\
\hline \multicolumn{8}{|l|}{ L. aurea } \\
\hline G. Hatschbach et al. 71936 & 47,5 & 51,6 & 0,92 & oblato-esferoidal & 52,0 & 19,2 & 0,36 \\
\hline G. Hatschbach et al. 64610 & 48,0 & 52,6 & 0,91 & oblato-esferoidal & 51,9 & 20,0 & 0,38 \\
\hline \multicolumn{8}{|l|}{ L. barbata } \\
\hline G. Hatschbach 49827 \& F.J. Zelma & 54,5 & 57,0 & 0,95 & oblato-esferoidal & 58,1 & 32,6 & 0,56 \\
\hline G. Hatschbach et al. 68114 & 58,1 & 59,2 & 0,98 & oblato-esferoidal & 59,1 & 33,2 & 0,56 \\
\hline Gardner 4799 & 52,5 & 55,6 & 0,94 & oblato-esferoidal & 56,3 & 34,0 & 0,60 \\
\hline L. Netto s.n. & 59,1 & 61,2 & 0,96 & oblato-esferoidal & 61,1 & 34,3 & 0,56 \\
\hline \multicolumn{8}{|l|}{ L. chamissonis } \\
\hline $\begin{array}{l}\text { M.E.S. Paschoal \& J.R. Fabricante } \\
\text { L. cotoneaster }\end{array}$ & 43,6 & 47,1 & 0,92 & oblato-esferoidal & 46,3 & 19,2 & 0,41 \\
\hline G. Hatschbach 64965 et al. & 42,8 & 45,3 & 0,94 & oblato-esferoidal & 44,6 & 23,4 & 0,52 \\
\hline G. Hatschbach 45153 \& O. Guimarães & 39,8 & 40,8 & 0,97 & oblato-esferoidal & 41,1 & 25,5 & 0,62 \\
\hline \multicolumn{8}{|l|}{ L. coulonioides } \\
\hline M.B. Casari 1021\& D.S. Pedrosa 918 & 43,5 & 49,7 & 0,87 & suboblata & 47,5 & 28,2 & 0,59 \\
\hline W. Hoehne 3183 & 47,0 & 52,7 & 0,89 & oblato-esferoidal & 52,6 & 28,3 & 0,53 \\
\hline W. Hoehne 692 & 46,8 & 50,6 & 0,92 & oblato-esferoidal & 53,0 & 27,3 & 0,51 \\
\hline L. F. Aguiar 20 & 45,3 & 49,3 & 0,91 & oblato-esferoidal & 47,6 & 27,9 & 0,58 \\
\hline \multicolumn{8}{|l|}{ L. eriolepis } \\
\hline L. Roth 1814 & 52,8 & 57,8 & 0,91 & oblato-esferoidal & 56,7 & 24,8 & 0,43 \\
\hline R. Esteves \& V. Esteves 308 & 53,3 & 57,3 & 0,93 & oblato-esferoidal & 55,8 & 24,5 & 0,44 \\
\hline G. Hatschbach 14523 & 51,2 & 56,3 & 0,90 & oblato-esferoidal & 59,5 & 19,0 & 0,31 \\
\hline \multicolumn{8}{|l|}{ L. gnaphalioides } \\
\hline A.C. Brade 17407 & 49,5 & 56,5 & 0,87 & suboblata & 56,0 & 21,5 & 0,38 \\
\hline \multicolumn{8}{|l|}{ L. helophila } \\
\hline W. Hoehne 1095 & 43,5 & 49,0 & 0,88 & oblato-esferoidal & 50,0 & 16,5 & 0,33 \\
\hline \multicolumn{8}{|l|}{ L. lilacina } \\
\hline W.R. Anderson 8920 & 43,6 & 46,1 & 0,94 & oblato-esferoidal & 46,0 & 22,5 & 0,48 \\
\hline G. Hatschbach 52880 \& V. Nicolack & 45,7 & 46,4 & 0,98 & oblato-esferoidal & 45,9 & 22,7 & 0,49 \\
\hline \multicolumn{8}{|l|}{ L. macahensis } \\
\hline M. Leitran 412 & 50,5 & 57,1 & 0,88 & suboblata & 55,2 & 19,7 & 0,35 \\
\hline G. Martinelli 13353 & 51,5 & 58,7 & 0,87 & suboblata & 57,8 & 18,8 & 0,32 \\
\hline \multicolumn{8}{|l|}{ L. muricata } \\
\hline J.P.P. Carauta 6507 \& D.F. Lima 342 & 42,3 & 42,7 & 0,99 & oblato-esferoidal & 42,8 & 27,1 & 0,63 \\
\hline P.L. Krieger 13018 & 45,2 & 44,1 & 1,02 & prolato-esferoidal & 44,1 & 21,8 & 0,49 \\
\hline G. Hatschbach 51337 \& A.C. Cervi & 45,9 & 45,2 & 1,01 & prolato-esferoidal & 46,2 & 20,3 & 0,43 \\
\hline \multicolumn{8}{|l|}{ L. obtusifolia } \\
\hline Сиеzzо 4060 & 45,4 & 49,4 & 0,91 & oblato-esferoidal & 49,5 & 21,6 & 0,43 \\
\hline C. Curtiss 26 & 45,5 & 49,1 & 0,92 & oblato-esferoidal & 48,4 & 22,8 & 0,47 \\
\hline D. Araújo 9535 & 46,2 & 50,9 & 0,90 & oblato-esferoidal & 47,6 & 21,8 & 0,45 \\
\hline J.P. Lanna-Sobrinho & 45,2 & 50,0 & 0,90 & oblato-esferoidal & 48,6 & 22,0 & 0,45 \\
\hline
\end{tabular}




\begin{tabular}{|c|c|c|c|c|c|c|c|}
\hline Espécimens & $\begin{array}{c}\text { Diâmetro } \\
\text { polar } \\
\bar{x}\end{array}$ & $\begin{array}{c}\text { Diâmetro } \\
\text { equatorial } \\
\bar{x}\end{array}$ & $\mathrm{P} / \mathrm{E}$ & Forma & DEVP & LA & IAP \\
\hline \multicolumn{8}{|l|}{ L. psilostachya } \\
\hline J. Vidal 297 & 51,0 & 53,5 & 0,95 & oblato-esferoidal & 51,9 & 28,8 & 0,55 \\
\hline \multicolumn{8}{|l|}{ L. remotiflora } \\
\hline G. Hatschbach \& E. Barbosa 72145 & 45,2 & 47,7 & 0,94 & oblato-esferoidal & 48,0 & 16,6 & 0,34 \\
\hline L. Roth 1423 & 46,0 & 48,7 & 0,94 & oblato-esferoidal & 49,9 & 15,6 & 0,31 \\
\hline \multicolumn{8}{|l|}{ L. salzmannii } \\
\hline M.C. Vianna 1090 & 43,7 & 46,2 & 0,94 & oblato-esferoidal & 46,5 & 14,9 & 0,32 \\
\hline L.C.B.Cortes & 43,6 & 45,6 & 0,95 & oblato-esferoidal & 45,8 & 14,6 & 0,31 \\
\hline A.C. Brade 10443 & 52,7 & 54,8 & 0,96 & oblato-esferoidal & 55,0 & 15,5 & 0,28 \\
\hline W.N. Vidal 189 & 44,0 & 47,2 & 0,93 & oblato-esferoidal & 47,5 & 15,0 & 0,31 \\
\hline \multicolumn{8}{|l|}{ L. sericea } \\
\hline L. Duarte & 49,8 & 52,7 & 0,94 & oblato-esferoidal & 52,5 & 24,2 & 0,46 \\
\hline J.P.P. Carauta 5566 & 48,6 & 52,9 & 0,91 & oblato-esferoidal & 52,5 & 23,9 & 0,45 \\
\hline J.P.P. Carauta 6349 & 51,7 & 55,0 & 0,94 & oblato-esferoidal & 51,5 & 24,6 & 0,47 \\
\hline \multicolumn{8}{|l|}{ L. sororia } \\
\hline F. Segadas-Vianna, et al. R150087 & 40,8 & 46,5 & 0,88 & oblato-esferoidal & 46,4 & 26,2 & 0,56 \\
\hline F. Segadas-Vianna, et al. R153372 & 43,6 & 48,0 & 0,90 & oblato-esferoidal & 47,1 & 24,7 & 0,52 \\
\hline R. Romero, J.N. et al. 1135 & 46,8 & 49,6 & 0,94 & oblato-esferoidal & 49,5 & 25,2 & 0,50 \\
\hline \multicolumn{8}{|l|}{ L. spixiana } \\
\hline J. Vidal R 113438 & 59,6 & 64,0 & 0,93 & oblato-esferoidal & 64,8 & 25,0 & 0,38 \\
\hline J. Vidal R 113441 & 56,4 & 61,4 & 0,91 & oblato-esferoidal & 62,4 & 26,4 & 0,42 \\
\hline \multicolumn{8}{|l|}{ L. subsquarrosa } \\
\hline L.E. Mello-Filho 3329 et al. & 45,0 & 49,8 & 0,90 & oblato-esferoidal & 52,6 & 22,8 & 0,43 \\
\hline V.F. Ferreira 3400 & 45,5 & 50,2 & 0,90 & oblato-esferoidal & 52,5 & 23,1 & 0,44 \\
\hline D. Araujo 9392 & 43,6 & 46,2 & 0,94 & oblato-esferoidal & 47,7 & 20,4 & 0,42 \\
\hline \multicolumn{8}{|l|}{ L. vauthieriana } \\
\hline J. Semir \& A. M. Giulietti & 45,3 & 50,5 & 0,89 & oblato-esferoidal & 50,7 & 22,0 & 0,54 \\
\hline
\end{tabular}

Vasanthy et al. (1993) descreveram os grãos de pólen de Vernonieae (Asteraceae), Trichantereae (Acanthaceae) e Nothapodytes (Icacinaceae) usando padrões geométricos das lacunas com aspectos poliédricos, circulares e prismáticos. Para os grãos de pólen 3-colporados, equinolofados da tribo Vernonieae, os autores estabeleceram quatro tipos: tipo "Adenoon indicum", com um total de 33 lacunas; Vernonia anthelmintica tipo "1" os grãos de pólen com 29 lacunas e Vernonia anthelmintica tipo "2" com 35 lacunas e o quarto, tipo "Vernonia monosis" com 39 lacunas. Para organizarem esses tipos, Vasanthy et al. (1993) fizeram diagramas esquemáticos citando os diferentes modos pelos quais poderiam ocorrer combinações nos vários tipos de lacunas. No presente trabalho oito espécies puderam ser enquadradas em Vernonia anthelmintica tipo "1" por possuírem 29 lacunas e não apresentarem lacuna equatorial; 10 espécies ficaram subordinadas ao tipo “Adenoon indicum” por apresentarem 33 lacunas.
As demais espécies não tiveram correspondência com nenhum dos outros tipos, principalmente, pela presença de lacunas equatoriais.

Robinson (1999), usando como base trabalhos anteriores de diversos autores e, inclusive os de sua autoria (Robinson 1987a, b, c, 1988a, b, c, 1989, 1990), elaborou uma classificação genérica e subtribal das Vernonieae americanas. Nesses trabalhos fazendo uso de caracteres macro e micromorfológicos, dentre eles a Palinologia, o autor aceitou para as Vernoniinae americanas 25 gêneros e cerca de 406 espécies que surgiram da fragmentação do gênero Vernonia. O complexo Lepidaploa formado por nove gêneros, é caracterizado pelo autor por apresentar grãos de pólen equinolofados, com muros "rizomiformes". Para Robinson (1990), a forma equinolofada é mais primitiva do que a não lofada e do que a espinhosa e portanto, o padrão dos grãos de pólen do Complexo Lepidaploa foi considerado o mais primitivo da tribo. Para o gênero 
Tabela 6. Classsificação das espécies de Lepidaploa ocorrentes na região Sudeste do Brasil. Tipo de área apertural $(\mathrm{a}=$ dois muros transversais individualizando três lacunas ficando a endoabertura na lacuna mediana; $b=$ dois muros não totalmente fundidos ficando apenas próximos sem individualizar as três lacunas; $c=$ sem muros transversais formando uma grande área apertural). Padrão de organização das lacunas $(1=$ três lacunas aperturais, seis lacunas abaperturais, seis pares de lacunas paraperturais, seis lacunas interaperturais e duas lacunas polares; $2=$ igual ao primeiro mais três lacunas equatoriais; $3=$ três lacunas aperturais, seis lacunas abaperturais, seis pares de lacunas paraperturais, seis lacunas interaperturais, sem lacunas polares (forma de "Y"); 4 = igual ao primeiro mais três lacunas equatoriais).

Table 6. Classification of Lepidaploa species of the Southeast Region of Brazil. Type of apertural area $(\mathrm{a}=$ two transverse muri delimiting three lacunae, the endoaperture is in the median lacuna; $b=$ two muri not totally fused, not delimiting three lacunae; $\mathrm{c}=$ without transverse muri, apertural area large). The lacunae organization pattern $(1=$ three apertural lacunae, six abapertural lacunae, six interapertural lacunae pairs and two polar lacunae. $2=$ equal to the first plus three equatorial lacunae; $3=$ three apertural lacunae, six abapertural lacunae, six parapertural lacunae pairs, six interapertural lacunae, without polar lacunae ("y"shape); 4 = equal to the first plus three equatorial lacunae).

\begin{tabular}{|c|c|c|c|c|}
\hline Espécies & $\begin{array}{l}\text { Tipo de área } \\
\text { apertural }\end{array}$ & $\begin{array}{c}\text { Padrão de organização } \\
\text { das lacunas }\end{array}$ & Tipo polínico & $\begin{array}{l}\text { Tipo polínico seg. } \\
\text { Robinson (1990) }\end{array}$ \\
\hline
\end{tabular}

\begin{tabular}{|c|c|c|c|c|}
\hline L. argyrotricha & $\mathrm{b}$ & 3 & G & $\mathrm{C}$ \\
\hline L. aurea & $\mathrm{a}$ & 3 & $\mathrm{D}$ & $\mathrm{D}$ \\
\hline L. barbata & $\mathrm{a}$ & 3 & $\mathrm{D}$ & $\mathrm{D}$ \\
\hline L. chamissonis & c & 1 & $X$ & $\mathrm{C}$ \\
\hline L. cotoneaster & $\mathrm{b}$ & 1 & $\mathrm{X}$ & $\mathrm{C}$ \\
\hline L. coulonioides & $\mathrm{a}$ & 3 & $\mathrm{D}$ & $\mathrm{C}$ \\
\hline L. decumbens & $\mathrm{c}$ & 3 & G & G \\
\hline L. eriolepis & $\mathrm{b}$ & 4 & G & G \\
\hline L. gnaphalioides & $\mathrm{b}$ & 4 & $\mathrm{X}$ & G \\
\hline L. gracilis & $\mathrm{b}$ & 1 & $\mathrm{X}$ & $\mathrm{C}$ \\
\hline L. helophila & $\mathrm{c}$ & 4 & G & G \\
\hline L. lilacina & $\mathrm{c}$ & 1 & $\mathrm{X}$ & $\mathrm{C}$ \\
\hline L. macahensis & c & 1 & $\mathrm{X}$ & $\mathrm{C}$ \\
\hline L. muricata & c & 1 & $\mathrm{X}$ & $\mathrm{G}$ \\
\hline L. obtusifolia & $\mathrm{c}$ & 2 & $\mathrm{C}$ & $\mathrm{C}$ \\
\hline L. psilostachya & $\mathrm{b}$ & 3 & $\mathrm{X}$ & $\mathrm{B} / \mathrm{G}$ \\
\hline L. remotiflora & $\mathrm{b}$ & 3 & $\mathrm{X}$ & G \\
\hline L. salzmannii & $\mathrm{b}$ & 1 & $\mathrm{X}$ & $\mathrm{C}$ \\
\hline L. sericea & $\mathrm{b}$ & 4 & $\mathrm{X}$ & $\mathrm{C}$ \\
\hline L. sororia & $\mathrm{c}$ & 3 & G & $\mathrm{G}$ \\
\hline L. spixiana & $\mathrm{a}$ & 3 & $\mathrm{D}$ & - \\
\hline L. subsquarrosa & $\mathrm{b}$ & 3 & G & G \\
\hline L. vauthieriana & $\mathrm{c}$ & 1 & $\mathrm{X}$ & - \\
\hline
\end{tabular}

Lepidaploa Robinson (1990, 1999) considerou a existência de quatro tipos polínicos. Dos 23 táxons aqui estudados palinologicamente, 21 também o foram por Robinson (1990) que classificou-os nos tipos polínicos "B", "C", "D" e "G". Confrontando os resultados aqui obtidos com os de Robinson (1990) confirmou-se apenas os tipos "C", "D" e "G" encontrados em oito espécies; 12 espécies não puderam ser enquadradas em nenhum dos tipos criados pelo autor, seja pela ausência de lacuna equatorial, seja pelas características da lacuna apertural; e duas espécies foram classificadas em tipos diferentes daqueles do autor.
Mendonça \& Gonçalves-Esteves (2000) descreveram a morfologia polínica de algumas espécies da tribo Vernonieae da restinga de Carapebus, Rio de Janeiro e, dentre elas, Lepidaploa araujoa H. Rob. e Vernonia rufogrisea A. St.-Hil. [Lepidaploa rufogrisea (A. St.-Hil.) H. Rob.] que não puderam ser enquadradas nos tipos de Stix (1960), de Jones (1979) e nem, no de Robinson (1990), principalmente, por apresentarem cólporos. Nos estudos de Mendonça \& Gonçalves-Esteves (2000) os grãos de pólen de L. araujoa ficaram próximos daqueles aqui descritos como tendo exina com padrão de organização 1 e lacuna 
apertural tipo b, enquanto que em L. rufogrisea os grãos de pólen ficaram próximos daqueles aqui descritos como tendo padrão de organização tipo 3 e lacuna apertural tipo a.

Com base no presente trabalho pôde-se concluir que os grãos de pólen do gênero Lepidaploa apresentam quatro principais padrões de organização das malhas da exina equinolofada e, três desses padrões podem ser dividos em subtipos de acordo com a forma da lacuna apertural. Assim, não se pôde utilizar, integralmente, os tipos já existentes para os grãos de pólen equinolofados criados por Robinson (1990).

Agradecimentos - Ao Laboratório de Ultraestrutura Celular, do Instituto de Biofísica da Universidade Federal do Rio de Janeiro (UFRJ), na pessoa da técnica de microscopia eletrônica de varredura, Nôemia Rodrigues Gonçalves. À Faperj (Proc. E-26/171.071/03), ao CNPq (Proc. 481595/2004-0) e pela bolsa de produtividade da terceira autora, à CAPES (pela bolsa de doutorado da primeira autora).

\section{Referências bibliográficas}

BAKER, J.G. 1873. Stilpnopappus. In: Flora brasiliensis (C.F.P. Martius \& A.G. Eichler, eds.). F. Fleischer, Lipsiae, v.6, pars 3, p.134-141.

BOLICK, M. \& KEELEY, S. 1994. Pollen morphology and classification of the Vernonieae (Compositae). Acta Botanica Gallica 141:279-284.

BREMER, K. 1994. Asteraceae: Cladistics and classification. Timber Press, Portland.

CABRERA, A.L. 1944. Vernonieas argentinas (Compositae). Darwiniana 6:265-379.

DE CANDOLE, A.P. 1836. Compositae-Eupatoriaceae, part I. In Prodromus systematis regni vegetabilis. (A.P. De Candolle, ed.). Treuttel \& Würtz, Paris, v.5, p.103-211.

ERDTMAN, G. 1952. Pollen morphology and plant taxonomy - angiosperms. Almqvisit \& Wiksell, Stockholm.

FAEGRI, G. \& IVERSEN, J. 1966. Textbook of modern pollen analysis. $2^{\text {nd }}$ ed. Scandinavian University Books, Copenhagen.

HIND, D.J.N. 1993. Notes on the Compositae of Bahia, Brazil: I. Kew Bulletin 48:245-277.

HIND, D.J.N.1999. A new rosulate species of Vernonia (Compositae: Vernonieae) from Bahia, Brazil. Kew Bulletin 54:905-913.

HOLMGREN, P.K., HOLMGREN, N.H. \& BAINETT, L.G. 1990. Index Herbariorum. Part 1: The Herbaria of the world. $8^{\text {th }}$ ed., New York Botanical Garden, New York.

JONES, S.B. 1970. Scanning electron microscopy pollen as an aid to the Systematics of Vernonia (Compositae). Bulletin of the Torrey Botanical Club 97:325-335.

JONES, S.B. 1973. Revision of Vernonia Section Eremosis (Compositae) in North America. Brittonia 25:86-115.
JONES, S.B. 1979. Synopsis and pollen morphology of Vernonia (Composiae: Vernonieae) in the New World. Rhodora 81:425-447.

JONES, S.B. 1981. Synoptic classification and pollen morphology of Vernonia (Compositae: Vernonieae) in the old world. Rhodora 83:59-75.

JONES, S.B. 1982. The genera of Vernonieae (Compositae) in the southeastern United States. Journal of the Arnold Arboretum 63:489-507.

KEELEY, S.C. 1978. A revision of the west indian Vernonias (Compositae). Journal of the Arnold Arboretum 59:360-413.

KEELEY, S.C. \& JANSEN, R.K. 1994. Chloroplast DNA restriction site in the Vernonieae (Asteraceae), and initial appraisal of the relationship of new and old-world taxa and the monophyly of Vernonia. Plant Systematics and Evolution 193:249-265.

KEELEY, S.C. \& JONES, S. 1977. Taxonomic implications of external pollen morphology to Vernonia (Compositae) in the West Indies. American Journal of Botany 64:576-584.

KEELEY, S.C. \& JONES, S. 1979. Distribution of pollen types in Vernonia (Vernonieae - Compositae). Systematic Botany 4:195-202.

KEELEY, S.C. \& TURNER, B.L. 1990. A preliminary cladistic analysis of the genus Vernonia (Vernonieae: Asteraceae). Plant Systematics and Evolution 4(supplement):45-66.

KING, R.M. \& DAWSON, H.W. 1975. Cassini on Compositae 1-3. Oriole, New York.

KINGHAM, D.L. 1976. A study of the pollen morphology of tropical african and certain other Vernonieae (Compositae). Kew Bulletin 31:9-26.

MENDONÇA, C.B.F. \& GONÇALVES-ESTEVES, V. 2000. Morfologia polínica de algumas espécies da tribo Vernonieae (Compositae Giseke) ocorrentes na restinga de Carapebus, Rio de Janeiro. Hoehnea 27:31-142.

MOREIRA, A.X. 1969. Catálogo de pólens do Estado da Guanabara e arredores. Museu Nacional, Rio de Janeiro.

NAIR, P.K.K. \& LAWRENCE, R. 1985. Advances in pollenspore. v.14, Scholar Publishing House, Lucknow.

PUNT, W., BLACKMORE, S., NILSSON, S. \& THOMAS, A. 1999. Glossary of pollen and spore terminology. http:// www.biol.ruu.nl./ palaeo/glossary/glos-int.htm. (acesso em 18/04/2003).

ROBINSON, H. 1987a. Studies in the Lepidaploa Complex (Vernonieae: Asteraceae) II- The new genus Echinocoryne. Proceedings of the Biological Society of Washington 100:584-589.

ROBINSON, H. 1987b. Studies in the Lepidaploa Complex (Vernonieae: Asteraceae) I- The genus Stenocephalum. Proceedings of the Biological Society of Washington 100:578-583.

ROBINSON, H. 1987c. Studies in the Lepidaploa Complex (Vernonieae: Asteraceae) III - Two new genus Cyrtocymura and Eirmocephala. Proceedings of the Biological Society of Washington 100:844-855. 
ROBINSON, H. 1988a. Studies in the Lepidaploa Complex (Vernonieae: Asteraceae) V - The new genus Chrysolaena. Proceedings of the Biological Society of Washington 101:952-958.

ROBINSON, H. 1988b. Studies in the Lepidaploa Complex (Vernonieae: Asteraceae) VI - A genus, Aynia. Proceedings of the Biological Society of Washington 101:959-965.

ROBINSON, H. 1988c. Studies in the Lepidaploa Complex (Vernonieae: Asteraceae) IV - The new genus, Lessingianthus. Proceedings of the Biological Society of Washington 101:929-951.

ROBINSON, H. 1989. Acilepidopsis, a new genus of Vernonieae from South America (Asteraceae). Phytologia 67:289-292.

ROBINSON, H. 1990. Studies in the Lepidaploa Complex (Vernonieae: Asteraceae) VII - The new genus, Lepidaploa. Proceedings of the Biological Society of Washington 103:464-498.

ROBINSON, H. 1994. Cololobus, Pseudopiptocarpha, and Trepadonia, 3 new genera from South-America (Vernonieae-Asteraceae). Proceedings of the Biological Society of Washington 107:557-568.

ROBINSON, H. 1996. The Paralychnophora group of Eremanthus (Vernonieae: Asteraceae) Rhodora 98:85-93.

ROBINSON, H. 1999. Generic and subtribal classification of American Vernonieae. Washington, Smithsonian Contributions to Botany 89:1-116.

ROUBIK, D.W. \& MORENO, P.J.E. 1991. Pollen and spores of Barro Colorado Island. Missouri Botanical Garden, New York.
SALGADO-LABOURIAU, M.L. 1973. Contribuição à palinologia dos cerrados. Academia Brasileira de Ciências, Rio de Janeiro.

SKVARLA, J.J. \& TURNER, B.L. 1966. Systematic implications from electron microscopic studies of Compositae pollen - a review. Annals of the Missouri Botanical Garden 53:220-256.

SKVARLA, J.J., TURNER, B.L., PATEL, V.C. \& TOMB, A.S. 1977. The pollen morphology in the Compositae and in morphologically related families. In: The biology and chemistry of the Compositae (V.H. Heywood, J.B. Harborne \& B.L. Turner, eds.). Academic Press, London. v.1, p.141-248.

SKVARLA, J.J., DEVORE, M.L. \& CHISSOE, W.F. 2005. Lophate sculpturing of Vernonieae (Compositae) pollen. Review of Palaeobotany and Palynology 133:51-68.

SMITH, C.E.J. 1969. Pollen characteristics of African species of Vernonia. Journal of the Arnold Arboretum 50:469-477.

STIX, E. 1960. Pollenmorpholosgische untersuchungen na Compositen. Grana Palynologica 2:41-114.

VASANTHY, G., FRANCESCHI, D. \& POCOCK, S. 1993. Geometric aspects of pollen: polyhedrons (VernonieaeAsteraceae), rotated symmetric (Trichanthereae Acanthaceae) and pyramidal to prismatic spinules (Nothapodytes-Icacinaceae). Grana 2(supplement):37-43.

WODEHOUSE, R.P. 1935. Pollen grains - Their structure, identification and significance in science and medicine. McGraw Hill, London. 